\title{
Systematic Integrated Process Design and Control of Binary Element Reactive Distillation Processes
}

\author{
Mansouri, Seyed Soheil; Sales-Cruz, Mauricio; Huusom, Jakob Kjøbsted; Gani, Rafiqul
}

Published in:

A I Ch E Journal

Link to article, DOI:

10.1002/aic. 15322

Publication date:

2016

Document Version

Peer reviewed version

Link back to DTU Orbit

Citation (APA):

Mansouri, S. S., Sales-Cruz, M., Huusom, J. K., \& Gani, R. (2016). Systematic Integrated Process Design and Control of Binary Element Reactive Distillation Processes. A I Ch E Journal, 62(9), 3137-3154.

https://doi.org/10.1002/aic.15322

\section{General rights}

Copyright and moral rights for the publications made accessible in the public portal are retained by the authors and/or other copyright owners and it is a condition of accessing publications that users recognise and abide by the legal requirements associated with these rights.

- Users may download and print one copy of any publication from the public portal for the purpose of private study or research.

- You may not further distribute the material or use it for any profit-making activity or commercial gain

- You may freely distribute the URL identifying the publication in the public portal 


\title{
Systematic Integrated Process Design and Control of Binary Element Reactive Distillation Processes*
}

\author{
Seyed Soheil Mansouri ${ }^{1}$, Mauricio Sales-Cruz ${ }^{2}$, Jakob Kjøbsted Huusom ${ }^{1}$, Rafiqul Gani ${ }^{1, \dagger}$ \\ ${ }^{1}$ Department of Chemical and Biochemical Engineering, Technical University of Denmark, Søltofts Plads, \\ Building 229, DK-2800 Kongens Lyngby, Denmark \\ ${ }^{2}$ Departamento de Procesos y Tecnología, Universidad Autónoma Metropolitana-Cuajimalpa, Artificios No. 40, \\ C.P. 01120, Ciudad de México, Mexico \\ ${ }^{\dagger}$ To whom correspondence should be addressed. E-mail: rag@kt.dtu.dk; Tel.: +45 45252882; Fax: +45

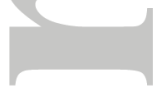 \\ 45932906
}

\section{Abstract}

In this work, integrated process design and control of reactive distillation processes is considered through a computer-aided framework. First, a set of simple design methods for reactive distillation column that are similar in concept to non-reactive distillation design methods are extended to designcontrol of reactive distillation columns. These methods are based on the element concept where the reacting system of compounds is represented as elements. When only two elements are needed to represent the reacting system of more than two compounds, a binary element system is identified. It is shown that the same design-control principles that apply to a non-reacting binary system of compounds are also valid for a reactive binary system of elements for distillation columns. Application of this framework shows that designing the reactive distillation process at the maximum driving force results in a feasible and reliable design of the process as well as the controller structure.

Topical Heading: Process Systems Engineering

Keywords: reactive distillation; process design; process control; driving force; computer-aided framework

\footnotetext{
${ }^{*}$ This article is an original extended version of the work presented at the $9^{\text {th }}$ International Symposium on Advanced Control of Chemical Processes (ADCHEM-9) held in Whistler, BC, Canada during 7-10 June, 2015 and published in the corresponding IFAC conference proceedings ${ }^{50}$.

This article has been accepted for publication and undergone full peer review but has not been through the copyediting, typesetting, pagination and proofreading process which may lead to differences between this version and the Version of Record. Please cite this article as doi: 10.1002/aic.15322 (C) 2016 American Institute of Chemical Engineers (AIChE) Received: Apr 02, 2016; Revised: May 13, 2016; Accepted: May 16, 2016
} 


\section{Introduction}

Process design and process control are usually considered as independent problems. In this context, a sequential approach is used where the process is designed first, followed by the design of process control. However, as it is well-known, this sequential approach has limitations related to dynamic constraint violations, for example, infeasible operating points, process overdesign or underperformance. Therefore, a robust performance may not always be guaranteed ${ }^{1,2}$ as process design decisions can influence process control and operation. To overcome these limitations, alternatives to tackle process design and controllability issues simultaneously, in the early stages of process design have been proposed and several reviews ${ }^{3-6}$ on this topic have been published recently. Huusom ${ }^{3}$ discussed the drivers for an integrated approach and outlines the challenges in formulation of such a multi-objective synthesis problem. Sharifzadeh ${ }^{4}$ and Ricardez-Sandoval et al. ${ }^{5}$ extensively reviewed the current state-of-the-art in integration of process design and control, while, Yuan et al. ${ }^{6}$ performed the review of the literature with a focus on optimization-based simultaneous design and control of chemical processes.

In control design, operability addresses stability and reliability of the process using a priori operational conditions and controllability addresses maintenance of process at desired operating points subject to disturbances $^{7}$. This simultaneous synthesis approach provides optimal/near optimal operation and more efficient control of chemical processes ${ }^{8}$. Most importantly, it is possible to identify and eliminate potentially promising design alternatives that may have controllability problems. To date, a number of methodologies have been proposed and applied on various problems to address the interactions between process design and control, and they range from mathematical programming optimizationbased approaches ${ }^{9}$ to model-based decomposition methods ${ }^{10}$. 


\section{(c)}

In mathematical optimization approaches, the process design problem is usually formulated as a mixed integer non-linear programming (MINLP) optimization problem. The continuous variables are linked with design variables (such as, flow rates, heat duties) and process variables (temperatures, pressures, compositions), while binary (decision) variables are used to model logical decisions related to choices between different process flowsheet alternatives. In the integrated process design-control context, the variables considered in the process model represent both steady-state and dynamic behavior of the process and in this case the optimization problem is referred to as mixed integer dynamic optimization $(\mathrm{MIDO})^{11}$. Meidanshahi and Adams ${ }^{12}$, addressed integrated process design and control of semicontinuous processes using a MIDO approach. Their results show that the MIDO approach using an outer approximation (OA) method was able to find similar solutions obtained with particle swarm optimization (PSO). Therefore, since the OA method proved to be faster than PSO, they recommended using PSO only when an OA method is not available.

In decomposition-based approach, the main idea is to decompose the original MINLP problem into an ordered set of sub-problems. Each sub-problem, except the last one, requires only the solution of a subset of the original constraints set. The final sub-problem contains the objective function and the remaining constraints. In this way, the solution of the decomposed set of sub-problems is equivalent to that of the original optimization problem. The advantage is a more flexible solution approach together with relatively easy to solve sub-problems while the disadvantage is that a global optimal solution cannot be guaranteed ${ }^{10}$. Mehta and Ricardez-Sandoval ${ }^{13}$, recently proposed a new methodology for integration of process design and control using power series expansion (PSE) approximations. The main idea in this approach is to back-off from the optimal steady-state design that is often found to be dynamically inoperable. However, the challenge in their approach is to determine the magnitude of the 
back-off needed to accommodate the transient and feasible operation of the process in the presence of disturbances and parameter uncertainty. Sharifzadeh and Thornhill ${ }^{14}$, proposed a new framework that utilizes a multi-objective function to explore the trade-off between process and control objectives. They applied two parallel solution strategies, dynamic optimization based on sequential integration and full discretization.

Another decomposition-based optimization approach has been proposed to tackle the integration of process design and controller design for reactor-separator-recycle processes ${ }^{15}$. The employed solution strategy is based on the targeted reverse design approach and employs thermodynamic-process insights, for example, the attainable region ${ }^{16}$ and the driving force concept ${ }^{17}$, to decompose the integrated design-control problem into four sequential hierarchical sub-problems ${ }^{10}$. Based on the solution of the decomposed set of hierarchical sub-problems, large number of infeasible solutions within the search space are identified and eliminated. Hence, it is able to obtain a final sub-problem that is significantly smaller in size.

Reactive distillation column (RDC) is a multifunctional unit operation, which incorporates separation and reaction in a single operation, attracting considerable interest in research from academia and industry ${ }^{18,19}$. Reactive distillation provides more sustainability, safer environmental performance as well as better energy management ${ }^{20}$. However, as a result of integration of functions/operations into one system the controllability region of reactive distillation processes may become smaller due to the loss in degrees of freedom; thereby making the process non-linear with highly interacting dynamics.

Various studies have addressed the design-control of reactive distillation processes. Al-Arfaj and Luyben ${ }^{21}$ explored six alternative control structures for an ideal two-product reactive distillation 
column. They illustrated the interaction between design and control by the impact of holdup in the reactive zone. Georgiadis et al. ${ }^{22}$ investigated the design and control of a RDC via two different optimization approaches. In the first approach, the steady-state process design and the control system are optimized sequentially. They confirmed that operability is strongly influenced by process design. In the second approach, the process design and the control system are optimized simultaneously using mixed integer dynamic optimization leading to a more economically beneficial and better controlled system than that obtained using the sequential approach. Therefore, the objective (or target) for the integrated process design and control is to overcome the bottlenecks associated with the sequential approach and to obtain optimal/near optimal design of a reactive distillation column which is also the easiest to control and operate. Patil et al. ${ }^{23}$, proposed a methodology that is focused on the simultaneous design, scheduling, and control of multiproduct processes. A key feature of their methodology is that it explicitly addresses the scheduling, design, and control issues simultaneously while taking into account the influence of process disturbances and uncertainty in the parameters in order to represent the actual operation of these processes.

In this work, integrated design and control of reactive distillation processes is considered through a systematic hierarchical approach implemented through a computer-aided framework. The framework, based on the method proposed by Hamid et al. ${ }^{10}$, consists of four hierarchical steps by which, (1) the objectives and design targets are set, (2) the number of elements in the system is identified, (3) the reactive distillation column is designed and the control structure is determined, and (4) the designed operation is verified by rigorous dynamic analysis. The paper is organized as follows: First, an overview of the concepts used is given. Next, the framework and implemented algorithms are presented. Finally, a case study highlighting the application of the framework is presented. Mathematical derivation details are given as appendix and as supplementary material. 


\section{Key concepts}

In this section some of the key concepts that are used in the development of the integrated designcontrol method, which is implemented within a computer-aided framework are briefly explained. These concepts are used in different algorithms throughout the framework and they facilitate adapting similar concepts that were originally developed for non-reactive distillation processes to be used also for design and control of binary element reactive distillation processes.

\section{Element concept}

The element concept is based on the determination of the minimum number of elements that can represent the reacting system and satisfying the atomic balance for all compounds (including inert compounds). The minimum number of elements is usually the number of compounds (reactants and products) involved in the reactions minus the number of reactions plus the number of inert compounds ${ }^{24}$. For example, in case of two reactants with molecular structure M1 and M2 and one product, it is always true (given that there is no stoichiometric constraint in the reaction such as the requirement of electrical neutrality in a system of electrolytes) that the product must have the molecular structure M1M2. Therefore, the three component system, in principle, can be represented with two elements for the specific reacting system.

\section{Chemical and physical equilibrium (CPE)}

This concept is derived from chemical model theory, where the equations of chemical equilibrium together with any appropriate physical model yielding the chemical potentials are embedded into an element-based model (called the chemical model) ${ }^{25}$. The solution of the chemical model equations together with the condition of equilibrium (equality of the component chemical potentials in all coexisting phases) provides the element phase compositions for the reactive system. One attractive 
feature of this concept is its capability to handle the problem of reactive-phase equilibrium in the same manner as the case when no reactions are taking place in the system. That is, this approach reduces the chemical and physical equilibrium problem to an identical physical equilibrium problem for a mixture of elements representing the system.

\section{Reactive driving force approach}

The reactive driving force is developed by Sanchez-Daza et al. ${ }^{24,26}$ and adapted from binary component separations (non-reactive) driving force ${ }^{27,28}$. It is defined as the difference in composition of a specific element between two co-existing phases. Note however, although the driving-force diagram is plotted for a binary pair of elements or compounds, since all separation tasks are performed for specific binary pairs of compounds (or elements), this concept can be applied also to multicompound mixtures as well. Also, the separation of a mixture of $N C$ compounds would need $N C-1$ separation tasks and therefore, $N C$-1 binary pairs of driving forces are involved for each separation task 28. Note that the element-based reactive driving-force diagram fully considers the extent of reaction on an element basis, and in this work it is applied in the design of reactive distillation columns for chemical equilibrium or kinetically controlled reactions ${ }^{25}$.

This approach provides the basis for the determination of important reactive distillation column design variables in terms of two parameters, the location and the size of the maximum driving force, $D_{x}$ and $D_{y}$, respectively. The feed stage location $\left(\mathrm{N}_{F}\right)$ and the minimum reflux ratio, $R R$ (and/or the reboil ratio, $R B)$ are determined from these two parameters for a given feed and product specification. A driving force diagram together with the distillation design parameters adapted from non-reactive binary separations is given in Figure 1.

Figure 1 should be inserted here. 


\section{$(7)$ \\ Integrated Process Design and Control}

The integrated process design and control is explained conceptually through the use of a process model represented by balance equations (mass, energy and momentum), constitutive equations (phenomena models usually as a function of intensive variables) and conditional equations (equilibrium, controller and defined relations). In a generic form, the model equations are given by,

$$
D=f(x, y, u, d, \theta, t)
$$

Where $D=d x / d t$ for dynamic model and $D=0$ for steady-state model.

Constitutive equations:

$\theta=g_{1}(u, x, y)$

Conditional equations:

$0=g_{2}(u, x, y, d, \delta)$

In Eqs. 1-3, $y$ is a vector of $N y$ output-controlled variables; $d$ is a vector of $N d$ feed stream-disturbance variables, $u$ is a vector of $N u$ design-manipulated variables; $\theta$ is a vector of constitutive variables; $x$ is a vector of $N x$ process-state variables and $\delta$ is vector of $N \delta$ controller parameters (needed for example, in closed-loop simulation of the process).

From a driving force based process design point of view, for specified inputs of design variables $(u)$ and disturbances in feed stream variables $(d)$, values for process variables $(x)$ and output variables $(y)$ that satisfy a set of design specifications (process design objectives) are determined at the maximum driving force. In this case $x$ and $y$ also define some of the operational conditions for the process. That is, values of variables $d$ and $u$ should be such that the desired process specifications (targets) of $x$ and $y$ 
are obtained, giving a feasible design. From multiple sets of values for these variables, the optimal design is found.

From a driving force based controller design point of view, for any changes in $d$ and/or set point values in $y$, values of $u$ that restores the process to its optimal designed condition are determined corresponding to the maximum driving force. That is, to maintain $x$ and $y$ at their target values for a disturbance in $d, u$ needs to be manipulated; or keeping $d$ fixed for a change in set-point for $y, u$ needs to be changed. Therefore, process design and control work with the same set of variables and the issue is how to select these variables (controller structure) and their values (design) ${ }^{29}$. It should be noted that the solution for $x$ and $y$ is directly influenced by $\theta$ (the constitutive variables such as reaction rate, equilibrium constant or driving force).

Consider the case where $y, u$, and $d$ are vectors of size 2, while $\theta$ and $x$ are scalers. The sensitivities of the controlled variables with respect to disturbances is given by the following equation,

$$
\frac{d y}{d d}=\left[\begin{array}{ll}
\frac{d y_{1}}{d d_{1}} & \frac{d y_{2}}{d d_{1}} \\
\frac{d y_{1}}{d d_{2}} & \frac{d y_{2}}{d d_{2}}
\end{array}\right]
$$

Similarly, the sensitivities of the controlled variables with respect to the manipulated variables is given by,

$$
\frac{d y}{d u}=\left[\begin{array}{ll}
\frac{d y_{1}}{d u_{1}} & \frac{d y_{2}}{d u_{1}} \\
\frac{d y_{1}}{d u_{2}} & \frac{d y_{2}}{d u_{2}}
\end{array}\right]
$$


Note that the constitutive Eq. 2, relates $\theta$ to $x$ (and $y$ ) and therefore, by integrating design-control of the process through the characteristics of $\theta$ with respect to $\theta$ to $x$ (and $y$ ) allows the calculation of the sensitivities of the controller sensitivity Eqs. 4a-4b through the following:

$$
\begin{aligned}
& {\left[\begin{array}{ll}
\frac{d y_{1}}{d d_{1}} & \frac{d y_{2}}{d d_{1}} \\
\frac{d y_{1}}{d d_{2}} & \frac{d y_{2}}{d d_{2}}
\end{array}\right]=\left[\begin{array}{ll}
\left(\frac{d y_{1}}{d \theta}\right)\left(\frac{d \theta}{d x}\right)\left(\frac{d x}{d d_{1}}\right) & \left(\frac{d y_{2}}{d \theta}\right)\left(\frac{d \theta}{d x}\right)\left(\frac{d x}{d d_{1}}\right) \\
\left(\frac{d y_{1}}{d \theta}\right)\left(\frac{d \theta}{d x}\right)\left(\frac{d x}{d d_{2}}\right) & \left(\frac{d y_{2}}{d \theta}\right)\left(\frac{d \theta}{d x}\right)\left(\frac{d x}{d d_{2}}\right)
\end{array}\right]} \\
& {\left[\begin{array}{ll}
\frac{d y_{1}}{d u_{1}} & \frac{d y_{2}}{d u_{1}} \\
\frac{d y_{1}}{d u_{2}} & \frac{d y_{2}}{d u_{2}}
\end{array}\right]=\left[\begin{array}{ll}
\left(\frac{d y_{1}}{d \theta}\right)\left(\frac{d \theta}{d x}\right)\left(\frac{d x}{d u_{1}}\right) & \left(\frac{d y_{2}}{d \theta}\right)\left(\frac{d \theta}{d x}\right)\left(\frac{d x}{d u_{1}}\right) \\
\left(\frac{d y_{1}}{d \theta}\right)\left(\frac{d \theta}{d x}\right)\left(\frac{d x}{d u_{2}}\right) & \left(\frac{d y_{2}}{d \theta}\right)\left(\frac{d \theta}{d x}\right)\left(\frac{d x}{d u_{2}}\right)
\end{array}\right]}
\end{aligned}
$$

Note that for the separation of a binary mixture, $\theta$ is the driving force (a scaler) and it is a concave function with respect to $x$ (liquid composition of one compound of the binary pair and so also a scaler) 28,29. A sample derivation of the terms of Eq. 5a corresponding to $d y_{1} / d d_{1}$ is given in Appendix A, for a specific version of the process model and its corresponding constitutive model and conditional equation involving a binary separation. Note that the derivative of driving force as a function of liquid composition is obtained directly from the constitutive model; the derivatives of $y$ with respect to driving force and $x$ with respect to disturbance variable are obtained from the process model equations (two independent version of the model) - see also Appendix A.

If $\mathrm{d} y / \mathrm{d} u$ or $\mathrm{d} x / \mathrm{d} u$ is small, the process sensitivity is low and process flexibility is high, while if $\mathrm{d} u / \mathrm{d} y$ or $\mathrm{d} u / \mathrm{d} x$ is large, process gain is high. Since values for $\mathrm{d} \theta / \mathrm{d} x$ is readily obtained from Eq. 2 , constitutive equations, and since $\mathrm{d} u / \mathrm{d} \theta$ is usually constant (linear dependence of $u$ on $\theta$ - since $\theta$ is a function of $x$ and $y-$ see Eq. 2), it is possible to gain useful insights related to integrated design and control issues 
(controller structure) without a rigorous solution of the process model equations. Note however, that the measured (control) variable is related to the process variable through $y=f(x, \theta)$; the process is designed with respect to the driving force; the set-point values for $y$ and $u$ are determined corresponding to the maximum driving force obtained from the constitutive equation ${ }^{15}$. Note that Eq. $(4 a-5 a)$ and $(4 b-5 b)$ are used in algorithm 3.3 of the framework, and their detailed use can be found in Appendices B and C.

It should be noted that at the maximum driving force, the largest difference between vapor phase and liquid phase compositions is achieved. As the driving force approaches zero, separation of the corresponding key component/element $i$ from the mixture becomes difficult, while, as the driving force approaches a maximum, the energy necessary to maintain the two-phase system is a minimum and the separation is the easiest. This is because the driving force is inversely proportional to the energy added to the system to create and maintain the two-phase (vapor-liquid) system. Thus, the process design corresponding to the driving force at the location of its maximum, integrates design and control.

This concept is illustrated through representation of a dynamic process system in Figure 2. The optimal solution for $x$ (states) and $y$ (outputs can be obtained at the maximum point of the reactive driving force (see diagram which is based on $\theta$ (the constitutive variables), $t$ is the independent variable (usually time) and $\delta$ is a controller parameter. The steady state model is obtained by setting $D=0$ in Eq. 1 . Otherwise, Equations 1-3 represent a dynamic model with a system of differential algebraic equations (DAEs). By using model analysis applied to these equations, the corresponding derivative information with respect to $x, y, u, d$ and $\theta$ are obtained (to satisfy controller design objectives).

Figure 2 should be inserted here. 


\section{(c)}

As stated above, solution of the balance equations for $x$ and $y$ is influenced by $\theta$ (the constitutive variables such as equilibrium constant or reaction rate). Also, since $x$ and $y$ are intensive variables, they may be used to formulate problems related to process synthesis, design and control. The analysis of the model equations, classifies the variables in terms of $x, y, u, d$ and $\theta$ for integrated design and control problems. This helps the selection of controller structure. Therefore, $\mathrm{d} \theta / \mathrm{d} x$ indirectly influences the process operation and controller structure selection and/or design.

\section{Integrated process design and control framework}

In this work, the case where the process flowsheet (reactive distillation process) is known together with the feed and process specifications is considered. The objective is to find the design variables, the operating conditions (including set-points for controlled variables) and controller structure that optimize the steady-state measures (energy consumption) and, simultaneously, a measure of the plant controllability, subject to a set of constraints, which ensure the desired dynamic behavior and satisfy the process specifications. Therefore, an integrated approach is employed where key variables together with their target values that have roles in process-controller design are identified; and, the resulting solution to the optimization problem addresses the trade-offs between conflicting design and control objectives.

The integrated process design and control problem is formulated as a generic mathematical optimization problem (see Eqs. 6-16) in which a performance objective function in terms of design, control and cost is optimized subject to a set of constraints: process (dynamic and steady state), constitutive (thermodynamic states) and conditional (process-control specifications) models-equations. Equation 6 represents the objective function which includes both the process design and controller 
design objectives, which can either be maximized or minimized. Equation 7 and Eq. 8 define a system of linear and nonlinear equations, for example, mass and energy balance (algebraic) equations representing a steady state and dynamic process model, respectively. Equation 9 and Eq. 10 represent the physical constraints and design specifications, respectively; and Eq. 11, because integration of functions/operations is also included in the process design problem, represents a set of constraints that the reactive distillation process must satisfy. Equations 12 and 13 represent and define the bounds on the design variables, $x$ (real) and decision variables $M$ (binary-integer), respectively, while Eq. 14 and Equation 15 represent the conditional process control constraints whereas Eq. 16 defines the controller structure.

$$
\begin{aligned}
& \min L=\sum_{i=1}^{m} \sum_{j=1}^{n} w_{i, j} J_{i, j} \\
& \text { s.t. } \\
& 0=g(x, u, \theta) \\
& \frac{d x}{d t}=f(x, y, d, u, \theta, t) \\
& b^{l} \leq B_{1} x+B_{2} y \leq b^{u} \\
& h^{l} \leq h(x, y) \leq h^{u} \\
& v^{l} \leq v(x, y) \leq y^{u} \\
& w^{l} \leq u(x, y) \leq w^{u} \\
& M_{j} \in\{0,1\}, j=1,2, \ldots n_{y}, x \geq 0
\end{aligned}
$$




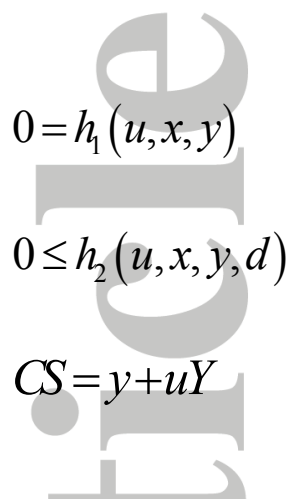

In Eqs. 6-16, $x$ and $y$ are regarded as the set of process variables in process design and as the set of state and/or controlled variables in controller design; they usually represent temperatures, pressures and compositions. $u$ is the set of design variables (for process design) and/or the set of manipulated variables (for controller design). $d$ is the set of disturbance variables, $\theta$ is the set of constitutive variables (physical properties, reaction rates), $v$ is the set of chemical system variables (molecular structure, reaction stoichiometry, etc.) and $t$ is the independent variable (usually time).

The optimization problem given by Eqs. 6-16 represents a MINLP problem. This problem can be difficult to solve if the process model consisting of balance, constitutive and process control equations is large and non-linear. In order to manage this complexity, a decomposition based solution approach where the problem is decomposed into a set of sub-problems that are solved according to pre-defined calculation order has been used in this work. This method is referred to as the decomposition based solution method ${ }^{30}$. Most of the sub-problems require bounded solution of a sub-set of equations. The final sub-problem is solved as a much reduced NLP or MINLP. The feasible alternatives are then evaluated using a set of performance related constraints (Eq. 11). For the remaining process alternatives, the objective function (Eq. 6) is calculated and ordered. Thereby, the highest or the lowest values of objective function can be easily identified. If the number of feasible alternatives is too large, the MINLP problem for a reduced size of the vector $y$ is solved. Alternatively, a set of NLPs for a fixed set of y can also be solved. This solution could be regarded as the best for specific problem definitions, 
the selected performance criteria, constraints, and, availability of data, parameters and models. A global optimal solution cannot be guaranteed with this method. In the context of this solution strategy, the solution from the decomposition based method may be used as a very good starting point for the solution of the MINLP problem for the direct solution strategy (solve all equations simultaneously).

Figure 3 illustrates work-flow implemented in the computer-aided framework for integrated process design and control of binary element reactive distillation processes. Note that Eqs. 1-16 correspond to each step of the framework as follows: Eqs. 9, 10, 11, 12, 13 are considered in Step 1; Eqs. 9, 10 are considered in Step 2; Eqs. 1, 2, 3, 4, 5, 7, 8, 9, 10, 11, 12, 13 are considered in Step 3; and Eqs. 1, 2, 3, $6,7,8,14,15,16$ are considered in Step 4.

Figure 3 should be inserted here.

\section{Step 1: Problem formulation/objective function definition}

The data/information on raw materials, products, catalysts, reaction conversions, and feed conditions (temperature, pressure, and composition) is collected in this step. Note that, this step starts after a decision to use a RDC has been made. Here, design targets and product specifications are given. Furthermore, the objective function which is to be maximized or minimized from both design and control perspectives is defined in this step.

\section{Step 2: Identify the number of elements present in the system}

In this step, the number of elements present in the reactive system is identified through algorithm 2.1.

\section{Algorithm 2.1: Identification of number of elements \\ Objective: To identify the number of elements present in the system}


Step (i): Calculate the number of elements using Eq. (17) where $N C$ is the number of compounds, and $N R$, is the number of reactions:

$$
N E=N C-N R
$$

Step (ii): If the number of elements $(N E)$ is equal to two go to Step (iii), otherwise, stop and return to Step (i). More than two elements will require the generation of reactive driving force for all binary pairs and selecting one according to developed rules ${ }^{31,32}$.

Step (iii): Write the formula matrix $\left(A_{e}\right)$ from the formula coefficients $a_{j i}$ with the constituent elements $(j=1,2, \ldots, N E)$ as rows and the species $(i=1,2, . ., N C)$ as columns ${ }^{33}$.

\section{Step 3: Reactive distillation column design}

The objective of this step is to find the design-control option for the reactive distillation column using the driving force approach.

\section{Step 3.1: Generate reactive vapor-liquid equilibrium (VLE) data}

The reactive equilibrium data are obtained either through availability of data or computation of reactive bubble points or dew points. If the data is not available, the reactive bubble point algorithm is used ${ }^{24}$. Below the algorithm to construct the reactive phase VLE diagram using the reactive bubble point algorithm is given.

\section{Algorithm 3.1: Construction of reactive phase VLE diagram}

Objective: To calculate the vapor-liquid equilibrium data at given temperature or pressure and element feed composition

Step (i): Give element composition in the feed $\left(W_{j}^{l}, j=1,2\right)$ and pressure $(P)$ 
Step (ii): Assume a temperature $(T)$ - This can be a temperature between bubble point and dew point. Step (iii): Solve for component moles $n_{i}^{l}$ in the liquid phase (chemical equilibrium). Note $N E=2$ in this work.

$$
\begin{array}{lr}
W_{j}^{l} \sum_{k=1}^{N E} \sum_{i=1}^{N C} A_{k i} n_{i}^{l}-\sum_{i=1}^{N C} A_{j i} n_{i}^{l}=0 & \text { for } j=1,2, . . N E \\
\sum_{i=1}^{N C} Z_{i, k} \mu_{i}^{l}=0 & \text { for } k=1,2, . . N R
\end{array}
$$

Step (iv): Compute vapor mole fractions $y_{i}$ at equilibrium implicitly.

$$
y_{i} \phi_{i}^{v}=x_{i} \phi_{i}^{l} \quad \text { for } i=1,2, . . N C
$$

Step (v): Calculate a correction for temperature using the check equation $\left(\sum_{i=1}^{N C} y_{i}-1=0\right)$. If not converged, return to Step (iii), else, go to Step (vi)

Step (vi): Compute element mole fractions for the vapor phase using below equation ${ }^{33}$ :

$$
W_{j}^{v}=\frac{\sum_{i=1}^{N C} A_{j i} y_{i}}{\sum_{k=1}^{N E} \sum_{i=1}^{N C} A_{k i} y_{i}}
$$

The element composition in the liquid phase is calculated using the below equation:

$$
W_{j}^{l}=\frac{\sum_{i=1}^{N C} A_{j i} x_{i}}{\sum_{k=1}^{N E} \sum_{i=1}^{N C} A_{k i} x_{i}}
$$

It should be noted that with the element mole fractions there is not any chance for obtaining negative values for composition variables.

Step (vii): Repeat Steps (i)-(vi) for new values of $W_{j}^{l}$ to obtain the reactive phase diagram for the entire composition domain (0-1). For systems without miscibility gaps, a constant discretization step of 0.05 in the $\mathrm{x}$-axis composition is used and recommended. Note that this phase diagram needs to be generated only once and it is not computationally expensive. 


\section{Step 3.2: Reactive distillation column design}

In order to obtain the reactive distillation design at the maximum driving force, algorithm 3.2 is applied. In this step, the reactive distillation column design at the maximum driving force is obtained. The reactive driving-force based on elements is calculated using Eq. 23 as described by Sanchez-Daza et al. ${ }^{24}$ :

$$
D F=W_{i}^{v}-W_{i}^{l}=\frac{W_{i}^{l} \alpha_{i j}}{1+W_{i}^{l}\left(\alpha_{i j}-1\right)}-W_{i}^{l}
$$

\section{Algorithm 3.2: Reactive distillation design using driving force approach}

Objective: To find the reactive distillation column design (number of stages, reflux ratio, feed location) at the maximum driving force using the specified design targets

Step (i): Retrieve vapor-liquid element data from algorithm 3.1.

Step (ii): Calculate the corresponding driving force for the entire composition domain using equation (23), then plot $|D F|$ versus $W_{i}^{l}$ based on the light key element.

Step (iii): Identify the area of operation of the driving force diagram, which is feed, distillate and bottom compositions based on the light key element using the design targets set in Step 1.

Step (iv): Determine the reflux ratio and reboil ratio. To do this, determine the slopes of lines $A D_{y}$ and $B D_{y}$ (see Figure 1). Determine the corresponding minimum reflux ratio $\left(R R_{\text {min }}\right)$ and reboil ratio $\left(R B_{\text {min }}\right)$. Next, Determine the real reflux ratio $(R R)$ and reboil ratio $(R B)$ from $R R=1.2\left(R R_{\min }\right)$ and $R B=1.2\left(R B_{\min }\right)$.

Step (v): If the number of stages, N, are given go to Step (vi), Else, use reactive McCabe-Thiele algorithm to obtain minimum number of stages (see 


\section{Appendix E, algorithm (I)).}

Step (vi): Identify the feed stage location, $\mathrm{N}_{F}$, from $\mathrm{N}_{F}=\mathrm{N}\left(1-D_{x}\right)$.

Step (vii): Check the design targets in terms of low key and heavy key elements in the feed, distillate and bottom as well as the location of maximum driving force on the $x$-axis $\left(D_{x}\right)$ with the following additional conditions. If one or more conditions given in Table 1 apply, use the guidelines to further retrofit the design.

a) If condition $1 \mathrm{a}$ is satisfied, then relocate NF between 5\% and $10 \%$ up in the column.

Else, if condition $1 \mathrm{~b}$ is satisfied, then relocate NF between $5 \%$ and $10 \%$ down in the column.

b) If condition $2 \mathrm{a}$ is satisfied then relocate NF $10 \%$ down.

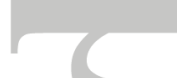

Else, if condition $2 \mathrm{~b}$ is satisfied, then relocate NF 5\% down.

Else, if condition 2c is satisfied, then relocate NF 5\% up.

Else, if condition $2 \mathrm{~d}$ is satisfied, then relocate NF $10 \%$ up.

Table 1 must be inserted here.

Step (viii): Perform steady-state simulation to confirm that the design targets are satisfied. These steady-state values are the nominal values for control.

After applying algorithm 3.2 for reactive driving force approach calculations, the optimal reactive distillation design option at the maximum driving force is obtained.

Step 3.3: Optimal design-control structure determination

The optimal design control structure determination is obtained analytically through the application of algorithm 3.3. 


\section{Algorithm 3.3: Optimal design-control structure determination}

Objective: The best controller structure at the maximum driving force is analytically identified by

applying this algorithm.

Step (i): Selection of controlled variables

In this algorithm, the primary controlled variable is $W_{A}^{l, m a x}\left(D_{x}\right)$, which is the $x$-axis value corresponding to the maximum driving force $\left(D_{\mathrm{y}}\right)$. The secondary controlled variables are the product composition (design targets), which are measurable variables and they are the distillate and bottom product purities of the light key element, $W_{A}{ }^{D}$ and $W_{A}{ }^{B}$, respectively. The reason behind this selection is that conceptual variables (that is driving force, $D F$ ) cannot be measured directly.

Step (ii): Sensitivity of controlled variables to disturbances

In order to calculate the sensitivity, apply a chain rule to relate the derivatives of primary controlled variable to the derivatives of the secondary controlled variables. In order to apply the chain rule, use the following key concepts:

- The desired element product at the top and the bottom is $W_{A}{ }^{D}$ and $W_{A}{ }^{B}$, the distillate and bottom composition of light key element (element A), respectively.

- At the maximum point of the driving force diagram, $W_{A}{ }^{D}$ and $W_{A}{ }^{B}$ (controlled variables) are the least sensitive to the imposed disturbances in the feed.

- The design variables vector is $y=\left[\begin{array}{ll}W_{A}{ }^{D} & W_{A}{ }^{B}\end{array}\right], x=W_{A}^{l}$ and $\theta=\mathrm{DF}$ is selected on the y-axis of the driving force diagram.

- The disturbance vector is, $d=\left[\begin{array}{ll}\mathrm{F}_{f} & \mathrm{Z}_{W A f}\end{array}\right]$ (feed flowrate and feed composition of element $A$ ). 
Therefore, the chain rule is expressed as in Eq. (24) using Eq. (4a) and (5a):

$$
\frac{d y}{d d}=\left[\begin{array}{ll}
\frac{d W_{A}^{D}}{d F_{f}} & \frac{d W_{A}^{D}}{d z_{W_{A f}}} \\
\frac{d W_{A}^{B}}{d F_{f}} & \frac{d W_{A}^{B}}{d z_{W_{A f}}}
\end{array}\right]=\left[\begin{array}{ll}
\left(\frac{d W_{A}^{D}}{d D F}\right)\left(\frac{d D F}{d W_{A}^{l}}\right)\left(\frac{d W_{A}^{l}}{d F_{f}}\right) & \left(\frac{d W_{A}^{D}}{d D F}\right)\left(\frac{d D F}{d W_{A}^{l}}\right)\left(\frac{d W_{A}^{l}}{d z_{W_{A f}}}\right) \\
\left(\frac{d W_{A}^{B}}{d D F}\right)\left(\frac{d D F}{d W_{A}^{l}}\right)\left(\frac{d W_{A}^{l}}{d F_{f}}\right) & \left.\left(\frac{d W_{A}^{B}}{d D F}\right)\left(\frac{d D F}{d W_{A}^{l}}\right)\left(\frac{d W_{A}^{l}}{d z_{W_{A f}}}\right)\right]
\end{array}\right]
$$

The value of Eq. (24) at the maximum driving force is obtained after some mathematical derivations are performed (see Appendix B for details). Having the derivatives in Eq. (24) derived analytically. The solution to Eq. (24) is expressed by Eq. (25).

$$
\begin{aligned}
& {\left[\left((R R+1)+\left(\frac{d D F}{W_{A}^{l}}\right)^{-1}\right)\left(\frac{d D F}{d W_{A}^{l}}\right)\left(\frac{a_{1}}{\left.\left[a_{2} \frac{d D F}{d W_{A}^{l}}+a_{3}+\left(\frac{d W_{A}^{D}}{d D F}\right)\left(\frac{d D F}{d W_{A}^{l}}\right)\right]\right)}\right]\right.}
\end{aligned}
$$

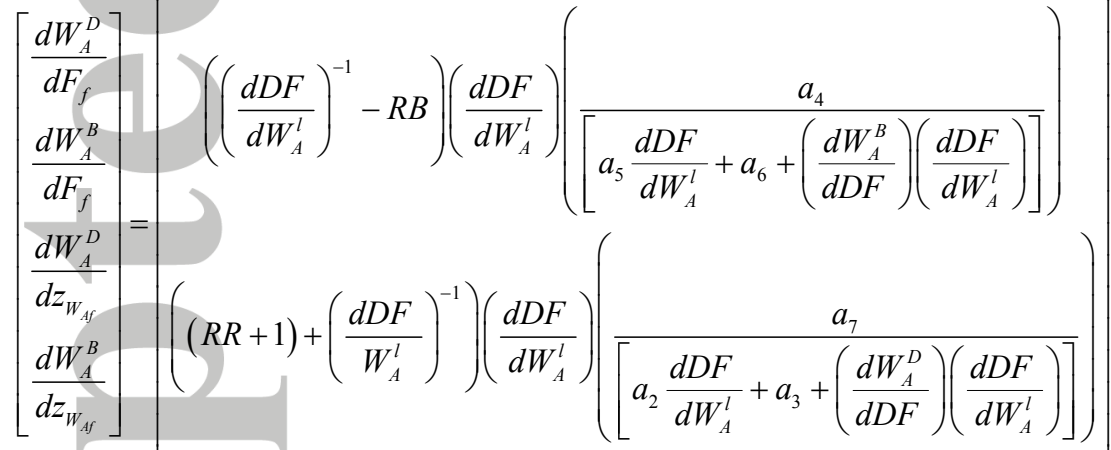

$$
\begin{aligned}
& {\left[\left(\left(\frac{d D F}{d W_{A}^{l}}\right)^{-1}-R B\right)\left(\frac{d D F}{d W_{A}^{l}}\right)\left(\frac{a_{8}}{\left[a_{5} \frac{d D F}{d W_{A}^{l}}+a_{6}+\left(\frac{d W_{A}^{B}}{d D F}\right)\left(\frac{d D F}{d W_{A}^{l}}\right)\right]}\right]\right.}
\end{aligned}
$$

It is noted that the driving force diagram is always concave with a unique maximum for nonazeotropic systems. It is also noted that the expressions for $\left(d W_{A}^{D} / d D F\right)\left(d D F / d W_{A}^{l}\right)$ and $\left(d W_{A}^{B} / d D F\right)\left(d D F / d W_{A}^{l}\right)$ in Eq. (25) are equal to 1 (note Eqs. (A.5) and (A.6) in Appendix B) at the 
maximum driving force and greater than 1 in any other point. Furthermore, at the maximum value of driving force diagram value of $\mathrm{dDF} / \mathrm{d} W_{A}^{l}$ is equal to zero. Therefore, Eq. (24) at the maximum driving force is expressed as:

$$
\frac{d y}{d d}=\left[\begin{array}{ll}
\frac{d W_{A}^{D}}{d F_{f}} & \frac{d W_{A}^{B}}{d F_{f}} \\
\frac{d W_{A}^{D}}{d z_{W_{A f}}} & \frac{d W_{A}^{B}}{d z_{W_{A f}}}
\end{array}\right] \approx\left[\begin{array}{ll}
(0)\left(\frac{a_{1}}{a_{3}+1}\right) & (0)\left(\frac{a_{4}}{a_{6}+1}\right) \\
(0)\left(\frac{a_{7}}{a_{3}+1}\right) & (0)\left(\frac{a_{8}}{a_{6}+1}\right)
\end{array}\right] \approx\left[\begin{array}{ll}
0 & 0 \\
0 & 0
\end{array}\right]
$$

Note that in Eq. (25) and (26), $a_{1}, \ldots, a_{8}$ are constants. Eq. (26) reveals that the sensitivity of controlled variables to disturbances in the feed is minimized at the maximum driving force.

Step (iii): Selection of the Controller Structure

The potential manipulated variables vector is $u=[\mathrm{L} \mathrm{V}]$, which are represented by reflux ratio (RR) and reboil ratio $(\mathrm{RB})$. Hence, the sensitivity of the secondary controlled variables to the manipulated variables is calculated by Eq. (27) (see Appendix C for derivation details).

$$
\frac{d y}{d u}=\left[\begin{array}{cc}
\frac{d W_{A}^{D}}{d R R} & \frac{d W_{A}^{D}}{d R B} \\
\frac{d W_{A}^{B}}{d R R} & \frac{d W_{A}^{B}}{d R B}
\end{array}\right]=\left[\begin{array}{cc}
D F+(R R+1)\left(\frac{d D F}{d W_{A}^{l}}\right)\left(\frac{d W_{A}^{l}}{d R R}\right)+\frac{d W_{A}^{l}}{d R R} & (R R+1)\left(\frac{d D F}{d W_{A}^{l}}\right)\left(\frac{d W_{A}^{l}}{d R B}\right)+\frac{d W_{A}^{l}}{d R B} \\
\frac{d W_{A}^{l}}{d R R}-\left(\frac{d D F}{d W_{A}^{l}}\right)\left(\frac{d W_{A}^{l}}{d R R}\right) R B & \frac{d W_{A}^{l}}{d R B}-D F
\end{array}\right]
$$

One can see from the driving force diagram that there is a well-defined maximum of $D F$ for a value of $W_{A}^{l}$. Since the process is designed at this point and the controller should maintain this set-point, thus the derivatives are evaluated at this point of $W_{A}^{l}$. Therefore, the value of $d D F / d W_{A}^{l}$ at the maximum driving force is equal to zero. Furthermore, assuming that $d W_{A}^{l} / d R R=d W_{A}^{l} / d R B=0 \quad\left(W_{A}^{l}\right.$ at the maximum driving force corresponds to $W_{A}^{l, m a x}$ which is a number. Thus, the derivative of the dependent variable that has a fixed value is zero), Eq. (27) is obtained (this corresponds to a system 
with no or little cross interactions between $y$ and $u$ since changes in $u$ cannot propagate through column). The best controller structure is easily determined by looking at the value of $\mathrm{d} y / \mathrm{d} u$. It is noted from Eq. (28) that since the values of $d W_{A}^{D} / d R R$ and $d W_{A}^{B} / d R B$ are bigger, controlling $W_{A}{ }^{D}$ by manipulating $R R$ and controlling $W_{A}{ }^{B}$ by manipulating $R B$ will require less control action. This is because only small changes in $R R$ and $R B$ are required to move $W_{A}{ }^{D}$ and $W_{A}{ }^{B}$ in a bigger direction. Therefore, for the optimal design obtained at the maximum driving force from algorithm 3.2, the control structure is always given by Eq. (28) and it is verified by analytical analysis that it is the optimal-design control structure.

$$
\frac{d y}{d u}=\left[\begin{array}{ll}
\frac{d W_{A}^{D}}{d R R} & \frac{d W_{A}^{D}}{d R B} \\
\frac{d W_{A}^{B}}{d R R} & \frac{d W_{A}^{B}}{d R B}
\end{array}\right]=\left[\begin{array}{cc}
D F & 0 \\
0 & -D F
\end{array}\right]
$$

Step 4: Dynamic analysis and verification

The objective of this step is to verify the optimal design-control structure determined from Step 3. This verification is performed in the forthcoming consecutive steps.

\section{Step 4.1: Control structure verification}

In this step algorithm 4.1 is applied to verify the control structure obtained from algorithm 3.3.

\section{Algorithm 4.1: Control structure verification}

Objective: To verify the control structure obtained at the maximum driving force using a rigorous dynamic model.

Step (i): Obtain the linear representation of the optimal design control option at the maximum driving 
force; that is, the transfer functions from step test between each manipulated $(u)$ and control variable $(y)$.

Step (ii): Construct the steady-state gain matrix $(G)$ from the transfer functions.

Step (iii): Verify that the gain matrix $G$ has non-zero determinant.

Step (iv): Calculate the relative gain matrix (RGA) using Eq. (29) as follows ${ }^{34}$ :

$$
R G A(G)=G \otimes\left(G^{-1}\right)^{T}
$$

Step (v): Verify that pairings such that the rearranged system, with the selected pairings along the diagonal, has an RGA matrix element close to unity, and off-diagonal elements close to zero (for a $2 \times 2$ system); therefore, control structure at the maximum driving force has least interactions with each other for the pairing given by Eq. (28).

Step 4.2: Dynamic evaluation of control structure

In this step, the performance of the control structure corresponding maximum driving force is evaluated through closed-loop simulations for disturbances in the feed. To this end, algorithm 4.2 is applied. Figure 4, depicts the closed-loop implementation concept in this framework.

Figure 4 must be inserted here. 


\section{Algorithm 4.2: Control structure evaluation}

Objective: To evaluate the performance of the control structure at the maximum driving force through closed-loop simulation

Step (i): Select a disturbance scenario in the feed.

Step (ii): Perform open-loop analysis in the presence of the disturbances (using a specified maximum in the disturbance size) to evaluate resulting transient responses.

Step (iii): Select Proportional-Integral controller as a control algorithm at regulatory level.

Step (iv): Retrieve nominal steady-state values for the control variables from algorithm 3.2-Step (viii) and use them as set-points.

Step (v): Select an appropriate tuning method (IMC rules ${ }^{35}$ or SIMC rules ${ }^{36}$ ) to obtain tuned controller parameters.

Step (vi): Perform closed-loop simulation and verify that the disturbance is rejected and the system is recovered to its original set-points.

Tools: A process simulator capable of performing dynamic and steady-state simulations is needed to perform this algorithm.

\section{Step 4.3: Final design selection}

In this step the value of the performance objective function or controller performance metrics (defined in Step 1) is calculated for the design-control option at the maximum driving force.

\section{Case study: MTBE synthesis}

The objective of this case study is to highlight the application of integrated process design and control framework with its associated algorithms and computer-aided tools. The design based on the driving 


\section{0}

force concept and the corresponding controller structure is to be determined and evaluated against two other controller structures corresponding to process designs that do not use the largest available driving force. The analysis results are also to be confirmed with closed-loop and open-loop simulations.

The process selected in this study to highlight the application of the integrated process design and control framework is the well-known production of Methyl Tert-Butyl Ether (MTBE) by reactive distillation. The reactive distillation technology for MTBE production has been studied ${ }^{37-39}$ and advantages of reactive distillation has been well established in the case of MTBE.

When chemical reactions take place very fast so that equilibrium is reached almost instantaneously, as it is the case for MTBE synthesis, the chemical equilibrium condition can be implicitly incorporated in element mass balances through the relationship between the phase compositions and the element chemical potentials $^{40}$. A dynamic model ${ }^{41}$ for the reactive distillation column is used in this case study. ICAS dynamic simulator is used to perform the simulations ${ }^{42}$.

\section{Step 1: Problem formulation/objective function definition}

The reaction of methanol with isobutene that yields MTBE takes place in presence of an acidic catalyst. The reaction is reversible and exothermic, with a heat of reaction of $-37.2 \mathrm{~kJ} / \mathrm{mol}$ in the liquid phase at $25^{\circ} \mathrm{C}^{43}$

isobutene $\left(\mathrm{C}_{4} \mathrm{H}_{8}\right)+$ methanol $\left(\mathrm{CH}_{4} \mathrm{O}\right) \leftrightarrow \operatorname{MTBE}\left(\mathrm{C}_{5} \mathrm{H}_{12} \mathrm{O}\right)$

Note however, it is assumed that there is no inert compound present in the system. The pure component properties (critical properties, molecular weights, boiling and melting points) are retrieved from ICAS- 
Database ${ }^{44}$. The feed conditions for production of MTBE are taken from Sánchez-Daza et al. ${ }^{24}$ and they are summarized in Table 2 .

Table 2 should be inserted here.

The design-control multi-objective performance function is defined as below:

$f_{\text {Obj }}=\min \left(J_{1}, J_{2}, J_{3}, J_{4}\right)$

In the above equation, a set of metrics are selected to the evaluate controller performance. They are: $J_{1}$ the sensitivity of the controlled variables to disturbances in the feed (dy/dd); $J_{2}$ the sensitivity of manipulated variables with respect to controlled variables $(\mathrm{du} / \mathrm{dy}) ; J_{3}$ measures the performance of the controller in terms of the integral of the absolute error (see Eq. 32); and $J_{4}$ measures the performance of the controller in terms of total variation of inputs (see Eq. 33).

$$
\begin{gathered}
J_{3}=I A E=\int_{0}^{\infty}\left|y-y_{s p}\right| d t \\
J_{4}=T V=\sum_{i=1}^{\infty}\left|u_{i+1}-u_{i}\right|
\end{gathered}
$$

\section{Step 2: Identify the number of elements present in the system}

In this step, algorithm 2.1 is applied. The number of elements present in the system is two with one reaction. The element matrix, choice of elements and element reaction are given in Table 3 .

Table 3 should be inserted here. 


\section{Step 3: Reactive distillation column design}

Step 3,1: Generate reactive vapor-liquid equilibrium (VLE) data

The reactive VLE data for the MTBE reactive system is calculated by applying algorithm 3.1 and using the Wilson model for liquid phase activity coefficients and SRK equation of state for vapor phase fugacity coefficients. The calculated reactive bubble points for entire composition space are given in Table 4 and Figure 5 presents the $T-W_{A}^{v}-W_{A}^{l}$ phase diagram for MTBE reactive system.

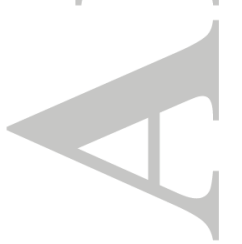

Table 4 should be inserted here.

Figure 5 should be inserted here.

\section{Step 3.2: Reactive distillation column design}

In this step, algorithm 3.2 is applied. The VLE data are retrieved from algorithm 3.1 and the reactive driving force diagram is constructed (see Figure S1 in supplementary material of this article). The area of operation is identified on the $x$-axis of the reactive driving force diagram in terms of light key element (see Appendix D for details). The point $D_{x}$ and $D_{y}$ corresponding to the maximum driving force are also identified and consequently slopes of operating lines are calculated which are used to determine $R R$ and $R B$. In this case study, the number of stages (N) is not given; therefore, algorithm (I) (reactive McCabe-Thiele method - see Appendix E) is applied. The results of application of algorithm (I) are given in Figure S2 in supplementary material of this article.

Note that from a practical point of view, presence of reaction in reboiler and condenser is infeasible and has not been reported in the literature to the best of authors' knowledge. Therefore, two non-reactive stages (i.e. partial reboiler and total condenser) are considered as stages. Thus, the total number of stages including reboiler and condenser is seven. Element feed, distillate and bottom compositions are 
checked against conditions given in Table 1 and it is found that condition 1(a) applies to the design specifications considered in this case study; therefore, the optimal feed location for the reactive distillation column design is at stage two from the top of the column. The final reactive distillation column design configuration at the maximum driving force is presented in Figure 6.

Figure 6 should be inserted here.

In order to confirm that the design targets are satisfied, steady-state simulation of the design is performed. It is readily observed from steady-state results (see Table 5) that the isobutene composition in the distillate is 98 mole\% and MTBE composition in the bottom is more than 84 mole $\%$ and the overall methanol conversion of $83.15 \%$ which match the design targets specified in Step 1.

Table 5 should be inserted here.

Step 3.3: Optimal design-control structure determination

The controlled variables $(y)$ are top and bottom compositions, manipulated variables $(u)$ are reflux ratio and reboiler duty (see Eq. 27). Moreover, the values of $d D F / d W_{A}^{l}$ are calculated and plotted versus $W_{A}^{l}$ (primary controlled variable) in Figure 7. It can be seen that the design at the maximum driving force has the least sensitivity of the controlled variables to the disturbances, and, the highest sensitivity to the manipulated variables. Since the reactive distillation column design is at the maximum driving force, the controller structure is given by Eq. 28 .

Figure 7 should be inserted here.

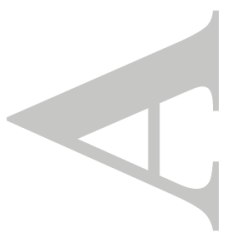


Step 4: Dynamic analysis and verification

Step 4,1: Control structure verification

In this step, algorithm 4.1 is applied. The transfer functions between each manipulated variable and controlled variable given by Eq. 28 are obtained by a step test and regressing the transfer function parameters ${ }^{45}$. The transfer functions have the form as Eq. 34:

$G(s)=K \frac{1+\tau_{z} s}{\left(1+\tau_{p 1} s\right)\left(1+\tau_{p 2} s\right)}$

The transfer function parameters for the design-control solution are given in Table 6. Note that manipulated variables $(u)$ are reflux ratio $(R R)$ and reboiler duty $\left(\mathrm{Q}_{\mathrm{R}}\right)$ while control variables $(y)$ are MTBE composition in the distillate $\left(x_{M T B E}^{D}\right)$ and bottom $\left(x_{M T B E}^{B}\right)$.

Table 6 should be inserted here.

Figure 8 shows the transfer function prediction of $R R / x_{M T B E}^{B}$ pair for the optimal design control-solution. The steady-state gain matrix $G$ is calculated and its corresponding determinant had a non-zero value.

Figure 8 should be inserted here.

The relative gain matrix is constructed using Eq. 29. The RGA values are then calculated given the potential control structures as in Eq. 28. The RGA matrix for optimal design-control solution is as follows:

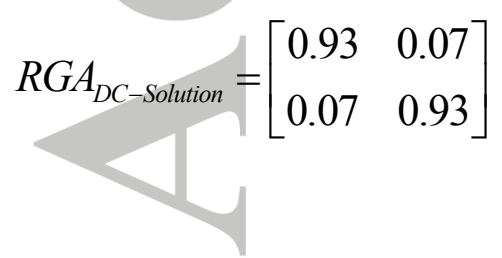


It is seen from the calculated RGA matrix, that the design-control solution has values close to unity on the diagonal (the control structure at the maximum driving force) and off-diagonal values close to zero. This verifies the analytical solution obtained at the maximum driving force for the determined optimal control structure.

\section{Step 4.2: Dynamic evaluation of control structure}

Figure 9 shows the dynamic open-loop response of the control variables to a $+15 \mathrm{kmol} / \mathrm{h}$ step change in the isobutene flowrate (from $70 \mathrm{kmole} / \mathrm{h}$ to $85 \mathrm{kmole} / \mathrm{h}$ ) after 15 samples (each time sample is 5 seconds). This disturbance results in a change in total feed flowrate and at the same time a change in the feed composition.

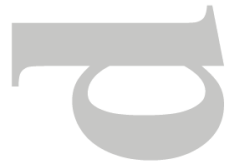

Figure 9 should be inserted here.

A proportional-integral (PI) controller is selected and its tuning parameters were calculated using the transfer functions in Table 6 (for selected control structure) and SIMC rules ${ }^{36}$. The control structure implementation on the reactive distillation column is depicted in Figure 10.

Figure 10 should be inserted here.

In Figure 10, control configuration in which the purities of both the top and the bottom products are measured and controlled is presented. This control structure implementation is in compliance with the relative gain array (RGA) analysis by which the composition of the MTBE in distillate is controlled by manipulating the reflux flow rate in the top control loop. In the bottom control loop, the composition of the MTBE in bottom is controlled by manipulating the heat duty of the reboiler. The levels of the reflux drum and the reboiler are controlled by the distillate and bottom-product flow rates, respectively. Note 
however, in this case study, the level controllers are proportional (P) type and they are included in the model equations for dynamic model consistency and stability. Furthermore, it is assumed that there is a perfect pressure control on the column and thus, the pressure changes in the column are neglected. Figure 11 shows the closed-loop performance of optimal design-control solution under the presence of the previously defined disturbance scenario.

Figure 11 should be inserted here.

It is verified in Figure 11 that the optimal design-control solution which is operating at the maximum driving force is able to reject the disturbance and restoring the control variables to their original setpoints with a relatively small effort in the manipulated variables in both top and bottom loops. It was, however, also expected from the RGA matrix since the values close to unity resemble the least interactions between the control loops, thereby, an easier disturbance rejection is facilitated.

\section{Step 4.3: Final design selection}

In the last step of the framework, the values of the controller performance metrics for the designcontrol solution are calculated and they are given in Table 7.

Table 7 should be inserted here.

As extra analysis and to further verify that the optimal design-control solution has been obtained, two candidate design alternatives which are not at the maximum driving force are selected. This selection is only to show that by going away from the maximum driving force the control of the reactive distillation process becomes more difficult. Therefore, in this comparison only the feed location is altered and the 


\section{(c)}

same controller structure and controlled variables as the ones at the maximum driving force are used for the consistency of the comparisons. These design candidates are summarized in Table 8.

Table 8 should be inserted here.

The dynamic analysis is performed for the design alternatives (1) and (2) following Steps $4.1-4.2$ of the framework. The candidate design alternatives both satisfied the design target and product specifications. Next, algorithm 4.1 was applied. The transfer functions were calculated and the corresponding RGA matrices were obtained as follows:

$$
\begin{aligned}
R G A_{\text {Alternative(1) }} & =\left[\begin{array}{cc}
9.06 & -8.06 \\
-8.06 & 9.06
\end{array}\right] \\
R G A_{\text {Alternative (2) }}= & =\left[\begin{array}{cc}
-0.28 & 1.28 \\
1.28 & -0.28
\end{array}\right]
\end{aligned}
$$

Design alternative (1) has a very large RGA element values for the selected pairing (diagonal) which means that the design is inherently difficult to control (Large RGA elements; typically, 5 - 10 or larger) for control indicate that the plant is fundamentally difficult to control due to strong input-output interactions $\left.{ }^{46}\right)$. In case of Design alternative (2), the values on diagonal are negative in which case the pairing is not recommended ${ }^{46}$. For the other potential structure in Design alternative (2), although the values are close to unity, the control structure is infeasible from a practical and physical point of view. Next, algorithm 4.2 was applied. Figure 12 shows the closed-loop performance of Design alternative (1) to a disturbance in the feed. As it can be seen, the top composition loop is oscillating with a diverging trend, whereas for the bottom control loop it may take a significantly long time to reject the disturbance. With respect to Design alternative (2), in Figure 13, one can observe how the large change in the bottom loop composition will eventually affect the top composition loop which again affects the 
Figure 12 should be inserted here.

Figure 13 should be inserted here.

Finally, the values of the performance metrics for the design-control alternatives are calculated and compared with the design-control solution at the maximum driving force. These values are given in Table 9. It confirms that the reactive distillation design at the maximum driving force has the minimum value of the performance metrics.

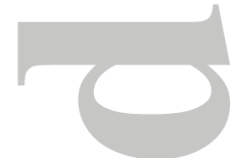

Table 9 should be inserted here.

\section{Conclusions}

In this work, integrated design and control of reactive distillation processes that can be represented by two elements, has been considered through an integrated design-control method implemented in a computer-aided framework. Process design and controller design issues have been considered simultaneously to assure that design decisions give the optimal controllability and economic performance. The framework is generic and can be applied to any reactive distillation process that is represented as a binary element system. Also, in principle, it should be applicable to any non-reactive distillation process separating a binary mixture. The framework utilizes a number of algorithms for design and control in different steps. The design methods and tools, which are similar in concept to non-reactive distillation design have been derived and implemented in the framework. These methods are based on the element concept. The application of the framework has been highlighted through the 
MTBE reactive distillation process. The optimal design-control solution has been verified and confirms the design-control corresponding to the maximum driving force is less sensitive to the disturbances in the feed and has the ability to reject disturbances with minimum interaction between the control loops. The design-control solution has been compared with alternative designs which are not at the maximum driving force. It has been shown that the designs that are not at the maximum driving force are more difficult to control. It also highlights in this case that process design can be identified that are easy to operate, control and needing low cost. The extension of the framework to handle reactive systems involving more than two elements as well as process flowsheets containing more than one unit operation have been developed and is reported in a new publication ${ }^{32}$. Also the use of a model predictive control algorithm will be highlighted in a future publication ${ }^{47}$.

\section{Appendix A: A sample derivation of the terms of controller sensitivity}

Let us consider a feed stream of flowrate $\mathrm{F}$ and composition $\mathrm{z}_{f}$ entering a binary distillation column operating at a fixed pressure P. At the top of the column, a liquid product $x^{D}$ is obtained and at the bottom a liquid product $x^{B}$ is obtained. Assuming that we have a binary mixture, $\mathrm{z}_{f}, x^{D}$ and $x^{B}$ represent the mole fractions of compound 1 (light key compound) in the feed, the top and the bottom product streams, respectively. Note that the mole fractions of compound 2 in these streams can be calculated using the condition equation $\left(\sum_{i}^{2} x_{i}=1\right)$ and therefore, are not independent variables. $x^{l}$ and $y^{v}$ are the liquid and vapor mole fractions leaving an equilibrium stage.

Derivation of $d x^{l} / d F_{f}$ :

The equation of the rectifying operating line is given by, 
$y^{v}=x^{D}\left[\frac{1}{R R+1}\right]+x^{l}\left[\frac{R R}{R R+1}\right]$

Subtracting $x^{l}$ from both sides, gives the following where DF is the driving force:

$D F=y^{v}-x^{l}=x_{d}\left[\frac{1}{R R+1}\right]+\left[\frac{R R}{R R+1}\right]-x^{l}$

Rearranging the above equation gives Eq. (A.19):

$x^{D}=(R R+1) D F+x^{l}$

Derivation of $d x^{D} / d D F$ :

The component mass balance can also be made for the total column, and inserting Eq. (A.19) into it, gives $\left(F_{f}\right.$ is the feed flowrate of compound $1-$ it is a disturbance variable).

$F_{f}=F \cdot z_{f}=(R R+1) D F \cdot D+D \cdot x^{l}+B \cdot x^{B}$

Eq. (A.19) can be differentiated with respect to driving force (DF) to give:

$\frac{d x^{D}}{d D F}=(R R+1)+\frac{d x^{l}}{d D F}$

Eq. (A.20) can be differentiated with respect to driving force $\left(F_{f}\right)$ to give:

$1=D(R R+1) \frac{d D F}{d F_{f}}+D \frac{d x^{l}}{d F_{f}}+B \frac{d x^{B}}{d F_{f}}$

Rearranging, gives the following: 
$\frac{1}{B}=\left(\frac{d x^{l}}{d F_{f}}\right)\left(\frac{d D F}{d x^{l}}\right)\left[\frac{D(R R+1)}{B}\right]+\left(\frac{d x^{B}}{d D F}\right)\left(\frac{d D F}{d x^{l}}\right)+\frac{D}{B}$

Derivation $d x^{l} / d D F$ :

Note that Eqs. (A.19) and (A.20) need $\mathrm{d} x^{l} / \mathrm{d} D F$, which is obtained from the equilibrium relation such

as,

$y^{v}=\frac{x^{l} \alpha}{1+x^{l}(\alpha-1)}$

Subtracting both sides by $x^{l}$, gives,

$D F=y^{v}-x^{l}=\frac{x^{l} \alpha}{1+x^{l}(\alpha-1)}-x^{l}$

Differentiating Eq. (A.25) with respect to $x^{l}$, gives $\mathrm{d} D F / \mathrm{d} x^{l}$. Given the measured/controlled variable vector $\mathbf{y}=\left[x^{D}, x^{B}\right]$, disturbance vector $\mathbf{d}=\left[F_{f}, \mathbf{z}_{f}\right], \mathbf{x}=\left[x^{l}\right]$ and $\theta=[D F]$, one by setting $\mathrm{y}_{1}=x^{D} ; \mathrm{d}_{1}=$ $F_{f} ; \mathrm{x}=x^{l}$ and $\theta=D F$, it is possible to use Eqs. (A.21) and (A.22 or A.23) and the derivative of Eq. (A.25) to obtain the right hand side of Eq. (4a-5a). Similarly, the right hand side of Eq. (5b) can also be obtained. Note that Eqs. (A.19), (A.20) and (A.25) are derived as a function of driving force, DF. The detailed derivation for a binary distillation system involving methanol-water is provided as supplementary material.

\section{Appendix B: Mathematical derivations for sensitivity of control variables to disturbances in the feed \\ The reactive element operating lines are given as follows ${ }^{41}$ :}




$$
W_{A}^{v}=\frac{R R}{R R+1} W_{A}^{l}+\frac{1}{R R+1} W_{A}^{D}
$$

$$
W_{A}^{v}=\frac{R B+1}{R B} W_{A}^{l}-\frac{1}{R B} W_{A}^{B}
$$

(Reactive operating line for the rectifying section)

(Reactive operating line for the stripping section)

Substituting these equations in Eq. (23) for $W_{A}^{\nu}$ gives the top and bottom element product composition with respect to the driving force as follows:

$$
\begin{aligned}
& W_{A}^{D}=D F(R R+1)+W_{A}^{l} \\
& W_{A}^{B}=W_{A}^{l}-D F \cdot R B
\end{aligned}
$$

Next, equations (A.3) and (A.4) are differentiated with respect to $D F$ (driving force) and result in the following expressions:

$$
\begin{aligned}
& \frac{d W_{A}^{D}}{d D F}=(R R+1)+\frac{d W_{A}^{l}}{d D F}=(R R+1)+\left(\frac{d D F}{W_{A}^{l}}\right)^{-1} \\
& \frac{d W_{A}^{B}}{d D F}=\frac{W_{A}^{l}}{d D F}-R B=\left(\frac{d D F}{d W_{A}^{l}}\right)^{-1}-R B
\end{aligned}
$$

The total element $A$ mass balance is written as follows:

$$
F_{f} \cdot z_{W_{A f}}=W_{A}^{D} b^{D}+W_{A}^{B} b^{B}
$$

Where, $b^{D}$ and $b^{B}$ are element $A$ mass flows in top and bottom of the column, respectively. Substituting (A.3) and (A.4), one at the time, into (A.7) for $W_{A}{ }^{D}$ and $W_{A}{ }^{B}$, the total element $A$ mass balance in terms of driving force is expressed as:

$$
F_{f} \cdot z_{W_{A f}}=D F(R R+1) b^{D}+W_{A}^{D} b^{D}+W_{A}^{B} b^{B}
$$


$F_{f} \cdot z_{W_{A f}}=W_{A}^{D} b^{D}+W_{A}^{B} b^{B}-b^{B} \cdot D F \cdot R B$

Differentiating equations (A.8) and (A.9) with respect to the $F_{f}$ and $z_{W A f}$ (assuming that the changes in composition, and, top and bottom element flowrates $\left(b^{D}\right.$ and $\left.b^{B}\right)$ with respect to the feed flowrate is negligible), the expressions for $d W_{A}^{l} / d F_{f}, d W_{A}^{l} / d z_{W_{A f}}$ are obtained. Having these derivatives, the solution to (24) is expressed by (25) as described in algorithm 3.3.

Note that a more detailed derivation for a binary compound system involving the methanol-water nonreactive system is given in the supplementary material of this paper.

\section{Appendix C: Mathematical derivations for control structure determination}

Equation (A.3) is differentiated with respect to RR as follows:

$$
\frac{d W_{A}^{D}}{d R R}=D F+(R R+1) \frac{d D F}{d R R}+\frac{d W_{A}^{l}}{d R R}
$$

The previous equation can be further expressed as a function of $\frac{d D F}{d W_{A}^{l}}$ as follows:

$$
\frac{d W_{A}^{D}}{d R R}=D F+(R R+1)\left(\frac{d D F}{d W_{A}^{l}}\right)\left(\frac{d W_{A}^{l}}{d R R}\right)+\frac{d W_{A}^{l}}{d R R}
$$

Differentiating the expression of the top product composition with respect to RB gives:

$$
\frac{d W_{A}^{D}}{d R B}=D F \frac{d R R}{d R B}+(R R+1) \frac{d D F}{d R B}+\frac{d W_{A}^{l}}{d R B}
$$

It is assumed that $\mathrm{d} R R / \mathrm{d} R B=0$, then equation is simplified and is expressed as a function of $\frac{d D F}{d W_{A}^{l}}$ as follows:

$$
\frac{d W_{A}^{D}}{d R B}=(R R+1)\left(\frac{d D F}{d W_{A}^{l}}\right)\left(\frac{d W_{A}^{l}}{d R B}\right)+\frac{d W_{A}^{l}}{d R B}
$$


The expression of the bottom product composition $\left(W_{A}^{B}\right)$ in terms of driving force is given by equation (A.4).

Differentiating the above equation with respect to $R R$ gives:

$$
\frac{d W_{A}^{B}}{d R R}=\frac{d W_{A}^{l}}{d R R}-\frac{d D F}{d R R} R B-D F \frac{d R B}{d R R}
$$

It is assumed that $\mathrm{d} R R / \mathrm{d} R B=0$, then the above equation is simplified and is expressed as a function of

$$
\begin{aligned}
& \text { as } \frac{d D F}{d W_{A}^{l}} \text { follows: } \\
& \frac{d W_{A}^{B}}{d R R}=\frac{d W_{A}^{l}}{d R R}-\left(\frac{d D F}{d W_{A}^{l}}\right)\left(\frac{d W_{A}^{l}}{d R R}\right) R B
\end{aligned}
$$

Similarly, differentiating the expression of bottom product composition $\left(W_{A}^{B}\right)$ with respect to $R B$ gives:

$$
\frac{d W_{A}^{B}}{d R B}=\frac{d W_{A}^{l}}{d R B}-D F
$$

Using these derivations, equation (27) is obtained.

Note that a more detailed derivation for a binary compound system involving the methanol-water nonreactive system is given in the supplementary material of this paper.

\section{Appendix D: Identification of area of operation based on elements}

In order to define the operating area to satisfy design objectives, consider the light key element liquid mole fraction obtained by Eq. (21). When $x_{1}=1$ (pure isobutene), and $x_{2}=x_{3}=0$, then, $W_{A}^{l}=1$ and $W_{B}^{l}=0$; and when $x_{2}=1$ (pure methanol), and $x_{1}=x_{2}=0$, then, $W_{A}^{l}=0$ and $W_{B}^{l}=1$. Therefore, when $x_{3}=1$ (pure MTBE), and $x_{1}=x_{2}=0$, then: $W_{A}^{l}=0.5$ and $W_{B}^{l}=0.5$. Having this simple evaluation performed, distillate ( $W_{A}^{D}$ ) and bottom $\left(W_{A}^{B}\right)$ are selected to be 0.99 and 0.5 on the $x$-axis of the reactive driving force 
diagram based on $W_{A}^{l}$ element composition. This selection is to ensure that the design targets can be satisfied.

\section{Appendix E: Reactive McCabe-Thiele}

Reactive McCabe-Thiele method is to calculate the minimum number of stages to obtain the desired product specifications (targets) in top and bottom of a binary element reactive distillation column. The method is based on the method proposed by McCabe and Thiele ${ }^{48}$ for non-reactive distillation design. Daza et al. ${ }^{24}$ have extended this method to also include reactive binary distillation columns (systems which can be represented by two elements, A and B). The design algorithm for binary element reactive distillation column is as follows:

\section{Algorithm (I): Reactive McCabe-Thiele method}

Step (i): Retrieve information form Step 3.1 and draw reactive equilibrium curve $\left(\mathrm{W}^{v}{ }^{-} \mathrm{W}_{A}^{l}\right.$ diagram for the light element, A)

Step (ii): Draw the angle bi-sector line ( $45^{\circ}$ line), locate $W_{\mathrm{A}, \mathrm{D}}^{l}$ (composition of element A in distillate), $W_{\mathrm{A}, \mathrm{B}}^{l}$ (composition of product $\mathrm{AB}$ in the bottom) and $W_{\mathrm{A}}^{F_{1}}$ (composition of element $\mathrm{A}$ in the feed) on the $45^{\circ}$ line.

Step (iii): Use the reflux ratio and reboil ratio obtained at the maximum driving force (algorithm 3.2) to calculate the slopes of the operating lines.

Step (iv): Draw the rectifying and stripping operating lines from $W_{\mathrm{A}, \mathrm{D}}^{l}$ and $W_{\mathrm{A}, \mathrm{B}}^{l}$ on the $45^{\circ}$ line. Find the minimum number of stages by drawing the steps.

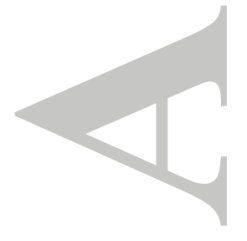




\section{Notation \\ Notation}

\section{Latin symbols}

$A \quad$ chemical element A

$A_{e} \quad$ formula matrix from the "natural" elements

$a_{j, i} \quad$ number of chemical elements $j$ present in species $i$

$B$ chemical element B

$b^{d}{ }_{T} \quad$ total element moles in the distillate

$b^{B}{ }_{T} \quad$ total element moles in the bottom

$b_{T}^{F}$ total element moles

$C$ chemical element $\mathrm{C}$

$d \quad$ aet of disturbance variables

DF driving force

$D_{x} \quad$ value on $x$-axis corresponding to maximum driving force

$D_{y} \quad$ value on $y$-axis corresponding to maximum driving force

$f_{\text {Obj }} \quad$ objective function

$f \quad$ a vector of non-linear equations

$F_{f} \quad$ element flowrate in the feed

$h^{l}, h^{u} \quad$ lower bounds and upper bounds of the linear and non-linear equations

$\mathrm{K} \quad$ steady-state gain

$M_{j} \quad$ the vector represents $0 / 1$ binary variables

$N \quad$ number of stages

$N_{F} \quad$ feed location

$N C$ number of compounds

$N E$ number of elements

$N R$ number of reactions

$P \quad$ pressure

$\mathrm{RR}$ reflux ratio

$\mathrm{RB}$ reboil ratio

$t \quad$ independent variable, time

$T$ temperature

$u$ set of input variables

$v^{l}, v^{u}$ lower bounds and upper bounds of chemical variables

$W_{j}^{k} \quad$ elemental mole fraction of element $j$ in the phase $k$

$W_{i}^{D}$ element mole fraction of $i$ in the distillate

$W_{i}^{B} \quad$ element mole fraction of $i$ in the bottom

$W_{L K, D}$ element mole fraction of light key element in the distillate

$W_{H K, D}$ element mole fraction of heavy key element in the distillate

$W_{H K, B}$ element mole fraction of heavy key element in the bottom

$W_{H K, z} \quad$ element mole fraction of heavy key element in the feed

$x_{i} \quad$ liquid mole fraction for component $i$

$x^{l} \quad$ liquid mole fraction

$y_{i} \quad$ vapor mole fraction for component $i$

$y^{v} \quad$ vapor mole fraction 


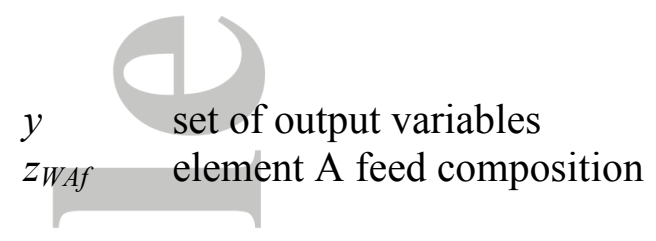

Greek letters

$\theta$ the constitutive variable

$\delta \quad$ controller parameter

$\alpha$ relative volatility

\section{Literature Cited}

1. Seferlis P, Georgiadis MC. The Integration of Process Design and Control. Comput Aided Chem Eng. 2004;17:1-639. http://www.sciencedirect.com/science/bookseries/15707946/17.

2. Dimian AC, Bildea CS, Kiss AA. Integrated Design and Simulation of Chemical Processes. Comput Aided Chem Eng. 2014;35:1-863.

3. Huusom JK. Challenges and opportunities in integration of design and control. Comput Chem Eng. 2015;81:138-146. doi:10.1016/j.compchemeng.2015.03.019.

4. Sharifzadeh M. Integration of process design and control: A review. Chem Eng Res Des. 2013;91(12):2515-2549. doi:10.1016/j.cherd.2013.05.007.

5. Ricardez-Sandoval LA, Budman HM, Douglas PL. Integration of design and control for chemical processes: A review of the literature and some recent results. Annu Rev Control. 2009;33(2):158-171. doi:10.1016/j.arcontrol.2009.06.001.

6. Yuan Z, Chen B, Sin G, Gani R. State-of-the-art and progress in the optimization-based simultaneous design and control for chemical processes. AIChE J. 2012;58(6):1640-1659. doi:10.1002/aic.13786.

7. Gollapalli U, Dantus MM, High KA. Environment and control issues in design. Comput Chem Eng. 2000;24(2-7):1709-1712. doi:10.1016/S0098-1354(00)80016-2. 
8. Nikačević NM, Huesman AEM, Van den Hof PMJ, Stankiewicz AI. Opportunities and challenges for process control in process intensification. Chem Eng Process Process Intensif. 2012;52:1-15. doi:10.1016/j.cep.2011.11.006.

9. Kookos IK, Perkins JD. An Algorithm for Simultaneous Process Design and Control. Ind Eng Chem Res. 2001;40(19):4079-4088. doi:10.1021/ie000622t.

10. Hamid MKA, Sin G, Gani R. Integration of process design and controller design for chemical processes using model-based methodology. Comput Chem Eng. 2010;34(5):683-699. doi:10.1016/j.compchemeng.2010.01.016.

11. Flores-Tlacuahuac A, Biegler LT. Simultaneous mixed-integer dynamic optimization for integrated design and control. Comput Chem Eng. 2007;31(5-6):588-600. doi:10.1016/j.compchemeng.2006.08.010.

12. Meidanshahi V, Adams TA. Integrated design and control of semicontinuous distillation systems utilizing mixed integer dynamic optimization. Comput Chem Eng. 2016;89:172-183. doi:10.1016/j.compchemeng.2016.03.022.

13. Mehta S, Ricardez-sandoval LA. Integration of Design and Control of Dynamic Systems under Uncertainty: A New Back-O ff Approach. Ind Eng Chem Res. 2016;55:485-498. doi:10.1021/acs.iecr.5b03522.

14. Sharifzadeh M, Thornhill NF. Integrated design and control using a dynamic inversely controlled process model. Comput Chem Eng. 2013;48:121-134. doi:10.1016/j.compchemeng.2012.08.009.

15. Hamid MKA. Model-Based Integrated Process Design and Controller Design of Chemical 
Processes. Kongens Lyngby: PhD Thesis, Technical University of Denmark; 2011.

16. Hildebrandt D, Glasser D. The attainable region and optimal reactor structures. Chem Eng Sci. 1990;45(8):2161-2168. doi:10.1016/0009-2509(90)80091-R.

17. Bek-Pedersen E, Gani R. Design and synthesis of distillation systems using a driving-forcebased approach. Chem Eng Process Process Intensif. 2004;43(3):251-262. doi:10.1016/S02552701(03)00120-X.

18. Harmsen GJ. Reactive distillation: The front-runner of industrial process intensification. Chem Eng Process Process Intensif. 2007;46(9):774-780. doi:10.1016/j.cep.2007.06.005.

19. Tuchlenski A, Beckmann A, Reusch D, Düssel R, Weidlich U, Janowsky R. Reactive distillation - industrial applications, process design \& scale-up. Chem Eng Sci. 2001;56(2):387-394. doi:10.1016/S0009-2509(00)00240-2.

20. Mansouri SS, Ismail MI, Babi DK, Simasatitkul L, Huusom JK, Gani R. Systematic Sustainable Process Design and Analysis of Biodiesel Processes. Processes. 2013;1(2):167-202. doi:10.3390/pr1020167.

21. Al-Arfaj M, Luyben WL. Comparison of Alternative Control Structures for an Ideal TwoProduct Reactive Distillation Column. Ind Eng Chem Res. 2000;39(9):3298-3307. doi:10.1021/ie990886j.

22. Georgiadis MC, Schenk M, Pistikopoulos EN, Gani R. The interactions of design, control and operability in reactive distillation systems. Comput Chem Eng. 2002;26(4-5):735-746. doi:10.1016/S0098-1354(01)00774-8.

23. Patil BP, Maia E, Ricardez-Sandoval LA. Integration of scheduling, design, and control of 
multiproduct chemical processes under uncertainty. AIChE J. 2015;61(8):2456-2470. doi:10.1002/aic.14833.

24. Sánchez-Daza O, Pérez-Cisneros ES, Bek-Pedersen E, Gani R. Graphical and Stage-to-Stage Methods for Reactive Distillation Column Design. AIChE J. 2003;49(11):2822-2841. doi:10.1002/aic.690491115.

25. Michelsen ML. Calculation of multiphase equilibrium. Comput Chem Eng. 1994;18(7):545-550. doi:10.1016/0098-1354(93)E0017-4.

26. Sánchez-Daza O, Pérez-Cisneros E, Bek-Pedersen E, Hostrup M. Tools for reactive distillation column design: Graphical and stage-to-stage computation methods. Comput Aided Chem Eng. 2001;9(C):517-522. doi:10.1016/S1570-7946(01)80081-X.

27. Bek-Pedersen E, Gani R, Levaux O. Determination of optimal energy efficient separation schemes based on driving forces. Comput Chem Eng. 2000;24(2-7):253-259. doi:10.1016/S0098-1354(00)00474-9.

28. Gani R, Bek-Pedersen E. Simple new algorithm for distillation column design. AIChE J. 2000;46(6):1271-1274. doi:10.1002/aic.690460619.

29. Russel BM, Henriksen JP, Jørgensen SB, Gani R. Integration of design and control through model analysis. Comput Chem Eng. 2002;26(2):213-225. doi:10.1016/S0098-1354(01)00742-6.

30. Karunanithi AT, Achenie LEK, Gani R. New Decomposition-Based Computer-Aided Molecular/Mixture Design Methodology for the Design of Optimal Solvents and Solvent Mixtures. Ind Eng Chem Res. 2005;44(13):4785-4797. doi:10.1021/ie049328h.

31. Mansouri SS, Sales-Cruz M, Huusom JK, Gani R. Integrated Process Design and Control of 46

AlChE Journal 
Multi-element Reactive Distillation Processes. In: IFAC DYCOPS-CAB 2016. 2016;Accepted.

32. Jantharasuk A, Gani R, Górak A, Assabumrungrat S. Methodology for design and analysis of reactive distillation involving multielement systems. Chem Eng Res Des. 2011;89(8):1295-1307.

doi:10.1016/j.cherd.2011.04.016.

33. Pérez-Cisneros ES, Gani R, Michelsen ML. Reactive separation systems-I. Computation of physical and chemical equilibrium. Chem Eng Sci. 1997;52(4):527-543. doi:10.1016/S00092509(96)00424-1.

34. Bristol E. On a new measure of interaction for multivariable process control. IEEE Trans Automat Contr. 1966;11(1):133-134. doi:10.1109/TAC.1966.1098266.

35. Rivera DE, Morari M, Skogestad S. Internal model control: PID controller design. Ind Eng Chem Res. 1986;25:252-265. doi:10.1021/i200032a041.

36. Skogestad S. Simple analytic rules for model reduction and PID controller tuning. J Process Control. 2003;13(4):291-309. doi:10.1016/S0959-1524(02)00062-8.

37. Schrans S, de Wolf S, Baur R. Dynamic simulation of reactive distillation: An MTBE case study. Comput Chem Eng. 1996;20(96):S1619-S1624. doi:10.1016/0098-1354(96)00275-X.

38. Sharma N, Singh K. Control of Reactive Distillation Column: A Review. Int J Chem React Eng. 2010;8(1). doi:10.2202/1542-6580.2260.

39. Grosser JH, Doherty MF, Malone MF. Modeling of reactive distillation systems. Ind Eng Chem Res. 1987;26(5):983-989. doi:10.1021/ie00065a023.

40. Pérez-Cisneros ES, Schenk M, Gani R, Pilavachi PA. Aspects of simulation, design and analysis 
of reactive distillation operations. Comput Chem Eng. 1996;20(96):S267-S272. doi:10.1016/0098-1354(96)00055-5.

41. Pérez-Cisneros ES. Modelling, Design and Analysis of Reactive Separation Processes. Kongens Lyngby: Ph.D. Thesis, Technical University of Denmark; 1997.

42. Gani R. ICAS Documentation. Kongens Lyngby: Internal Document, Technical University of Denmark; 2015.

43. Al-Jarallah AM, Lee AKK, Siddiqui MAB. Kinetics of methyl tertiary butyl ether synthesis catalyzed by sulphuric acid. Chem Eng J. 1988;39(3):169-174. doi:10.1016/03009467(88)80024-8.

44. Nielsen TL, Abildskov J, Harper PM, Papaeconomou I, Gani R. The CAPEC database. J Chem Eng Data. 2001;46(5):1041-1044. doi:10.1021/je000244z.

45. Pernebo L, Silverman LM. Model reduction via balanced state space representations. IEEE Trans Automat Contr. 1982;27(2):382-387. doi:10.1109/TAC.1982.1102945.

46. Skogestad S, Morari M. Implications of Large RGA Elements on Control Performance. Ind Eng Chem Res. 1987;26:2323-2330. doi:10.1021/ie00071a025.

47. Mansouri SS, Sales-cruz M, Huusom JK, Gani R. Systematic Integrated Process Design and Control of Reactive Distillation Processes Involving Multi-elements. Chem Eng Res Des. 2016;Submitted.

48. McCabe WL, Thiele E. Graphical design of fractionating columns. Ind Eng Chem. 1925;17(6):605-611. doi:10.1021/ie50186a023. 
49. Babi DK, Gani R. Hybrid Distillation Schemes: Design, Analysis, and Application. In: Gorak A, Sorensen E, eds. Distillation: Fundamentals and Principles. London: Elsevier; 2014:357-381. doi:10.1016/B978-0-12-386547-2.00009-0.

50. Mansouri SS, Sales-Cruz M, Huusom JK, Woodley JM, Gani R. Integrated Process Design and Control of Reactive Distillation Processes. IFAC-PapersOnLine. 2015;48(8):1120-1125. doi:10.1016/j.ifacol.2015.09.118.
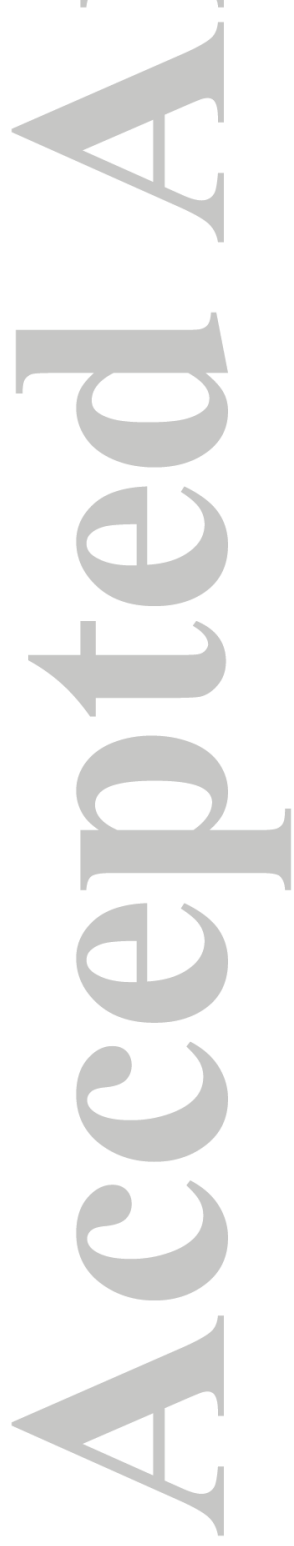


\section{List of Tables}

Table 1. Additional Conditions for Reactive Distillation Column Design using Driving Force Approach ${ }^{17,28}$

Table 2. Design Targets and Product Specifications for MTBE System

Table 3. The Element Matrix and Element Reaction for MTBE Reactive System (without Inert)

Table 4. Reactive Vapor-Liquid Equilibrium Data for MTBE Reactive System at $101.3 \mathrm{kPa}$

Table 5. Nominal Operating Point of the Optimal Design-control Solution

Table 6. Transfer Function Parameters for Design-control Alternatives

Table 7. The Value of Controller Performance Metrics

Table 8. Design Alternatives (Not at Maximum Driving Force) for Verification

Table 9. The Values of the Controller Performance Metrics for the Design-control Solution and Alternatives (1) and (2) 


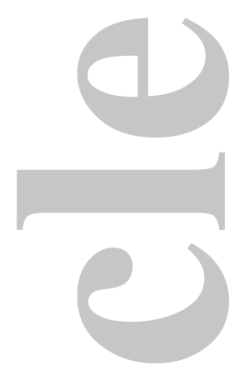

Table 1. Additional Conditions for Reactive Distillation Column Design using Driving Force

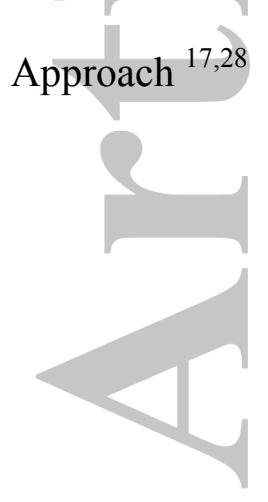

\section{Condition 1}

a)

$W_{H K, z}<0.8$ and $D_{x}<0.7$

b)

$W_{H K, z}<0.8_{\text {and }} D_{x}>0.3$

Condition 2

a)

$\frac{1-W_{L K, D}}{1-W_{H K, B}}<0.01$ and $D_{x}<0.7$

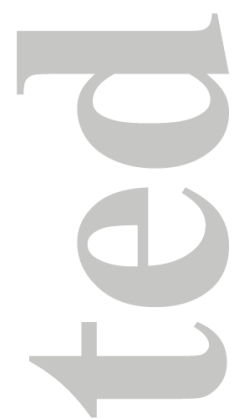

b)

$$
\frac{1-W_{L K, D}}{1-W_{H K, B}}<0.1 \text { and } D_{x}<0.7
$$

c)

$\frac{1-W_{H K, B}}{1-W_{L K, D}}<0.1$ and $D_{x}>0.3$

d)

$\frac{1-W_{H K, B}}{1-W_{L K, D}}<0.01$ and $D_{x}>0.3$




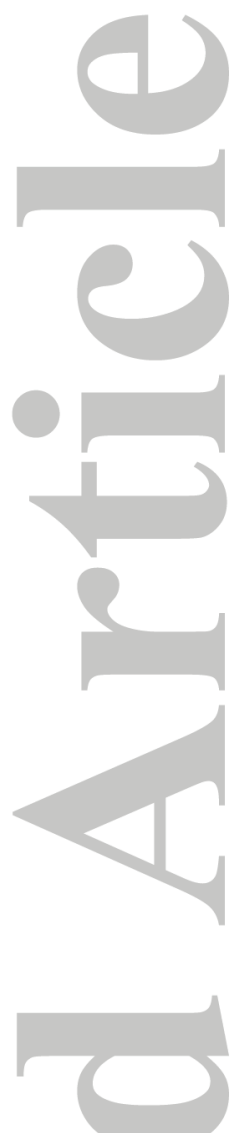

Table 2. Design Targets and Product Specifications for MTBE System

\begin{tabular}{llll}
\hline Component & \multicolumn{3}{c}{ Molar composition } \\
\hline & Feed & Distillate & Bottom \\
\cline { 2 - 4 } Isobutene $\left(\mathrm{C}_{4} \mathrm{H}_{8}\right)$ & 0.7 & 0.98 & - \\
Methanol $\left(\mathrm{CH}_{4} \mathrm{O}\right)$ & 0.3 & - & - \\
MTBE $\left(\mathrm{C}_{5} \mathrm{H}_{12} \mathrm{O}\right.$ & 0.0 & - & more than 0.8 \\
\hline Methanol conversion: more than $80 \%$; Feed flowrate: $100 \mathrm{kmol} / \mathrm{h} ;$ Feed temperature and pressure: $300 \mathrm{~K}$ and \\
$101.3 \mathrm{kPa}$; degree of vaporization $(q): 0.795$ & & \\
\hline
\end{tabular}




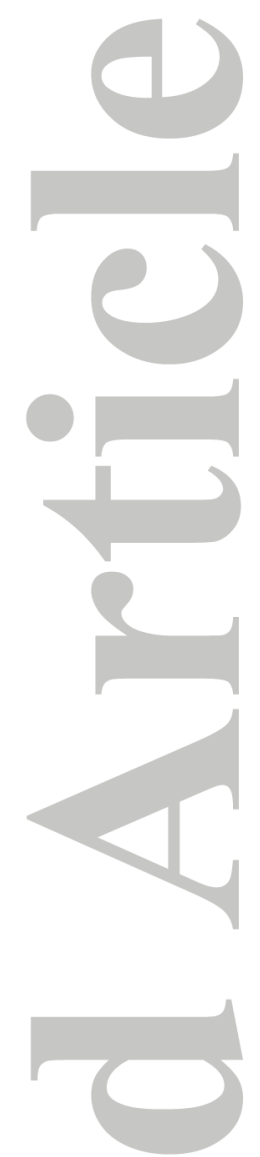

Table 3. The Element Matrix and Element Reaction for MTBE Reactive System (without Inert)

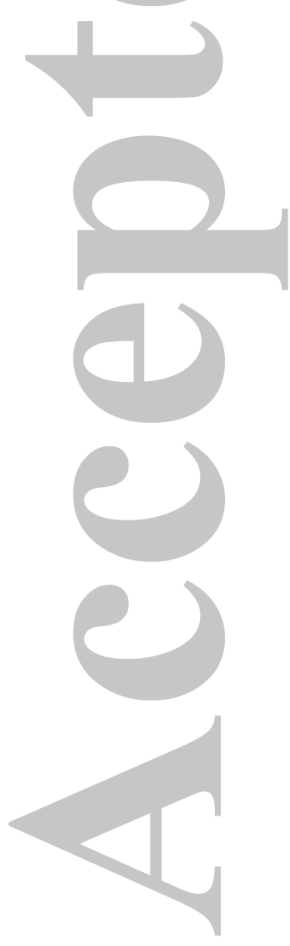

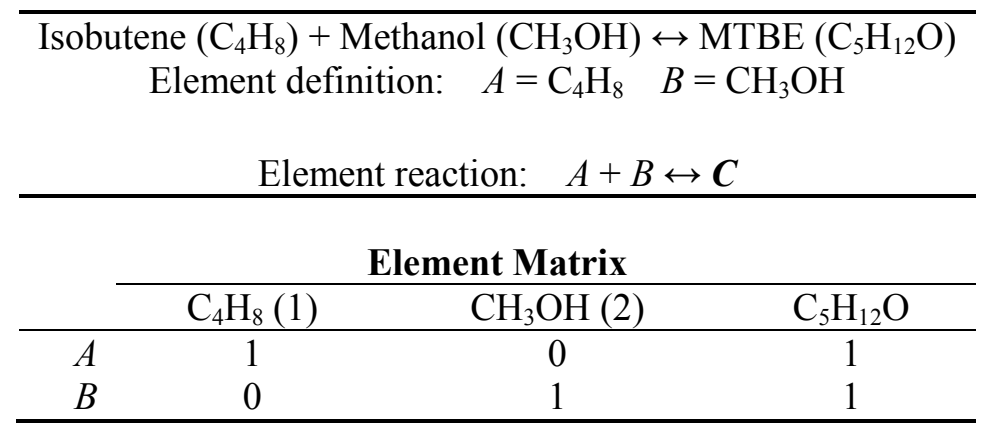

53

AlChE Journal

This article is protected by copyright. All rights reserved. 
Table 4. Reactive Vapor-Liquid Equilibrium Data for MTBE Reactive System at $101.3 \mathrm{kPa}$

\begin{tabular}{|c|c|c|c|c|c|c|c|c|c|c|c|}
\hline \multirow[t]{2}{*}{ i-Butene $\left(W_{A}\right)$} & \multirow[t]{2}{*}{ Temperature (K) } & \multicolumn{3}{|c|}{ Component vapor composition } & \multicolumn{3}{|c|}{ Component liquid composition } & \multicolumn{4}{|c|}{ Element compositions } \\
\hline & & $y(1)$ & $y(2)$ & $y(3)$ & $x(1)$ & $x(2)$ & $x(3)$ & $W_{A}^{l}$ & $W_{B}^{l}$ & $W_{A}^{v}$ & $W_{B}^{v}$ \\
\hline 0.01 & 337.53 & 4.37E-04 & 0.99547 & 0.00408 & $6.43 \mathrm{E}-06$ & 0.99899 & 0.00099 & 0.001 & 0.999 & 0.004 & 0.995 \\
\hline 0.05 & 334.11 & 0.0169 & 0.81473 & 0.16836 & 0.00032 & 0.94738 & 0.05229 & 0.050 & 0.950 & 0.159 & 0.790 \\
\hline 0.1 & 331.23 & 0.02759 & 0.68755 & 0.28484 & 0.00067 & 0.88896 & 0.11036 & 0.100 & 0.900 & 0.243 & 0.644 \\
\hline 0.15 & 329.05 & 0.03538 & 0.59459 & 0.37001 & 0.00108 & 0.82372 & 0.17519 & 0.150 & 0.850 & 0.296 & 0.536 \\
\hline 0.2 & 327.37 & 0.04187 & 0.52273 & 0.43539 & 0.00161 & 0.7504 & 0.24798 & 0.200 & 0.800 & 0.332 & 0.452 \\
\hline 0.25 & 326.06 & 0.04803 & 0.46383 & 0.48812 & 0.00230 & 0.66743 & 0.33026 & 0.250 & 0.750 & 0.360 & 0.385 \\
\hline 0.3 & 325.03 & 0.05475 & 0.41189 & 0.53334 & 0.00326 & 0.57282 & 0.4239 & 0.300 & 0.700 & 0.384 & 0.328 \\
\hline 0.35 & 324.21 & 0.06341 & 0.36097 & 0.57561 & 0.00470 & 0.46407 & 0.53122 & 0.350 & 0.650 & 0.406 & 0.277 \\
\hline 0.4 & 323.53 & 0.07759 & 0.30208 & 0.62031 & 0.00716 & 0.33811 & 0.65473 & 0.400 & 0.600 & 0.431 & 0.229 \\
\hline 0.45 & 322.84 & 0.11239 & 0.21477 & 0.67283 & 0.01290 & 0.19238 & 0.7947 & 0.450 & 0.550 & 0.469 & 0.182 \\
\hline 0.5 & 320.83 & 0.22288 & 0.09427 & 0.68284 & 0.03122 & 0.06921 & 0.89955 & 0.490 & 0.510 & 0.538 & 0.167 \\
\hline 0.55 & 301.29 & 0.70051 & 0.00265 & 0.29683 & 0.1845 & 0.00328 & 0.81221 & 0.550 & 0.450 & 0.769 & 0.388 \\
\hline 0.6 & 289.41 & 0.85004 & 0.00037 & 0.14958 & 0.33378 & 0.00067 & 0.66553 & 0.600 & 0.400 & 0.870 & 0.511 \\
\hline 0.65 & 282.52 & 0.90949 & 0.00011 & 0.09039 & 0.46166 & 0.00022 & 0.53811 & 0.650 & 0.350 & 0.917 & 0.591 \\
\hline 0.7 & 278.02 & 0.94019 & $4.46 \mathrm{E}-05$ & 0.05976 & 0.57146 & $9.63 \mathrm{E}-05$ & 0.42943 & 0.700 & 0.300 & 0.944 & 0.657 \\
\hline 0.75 & 274.82 & 0.95888 & $2.16 \mathrm{E}-05$ & 0.04109 & 0.66668 & 4.47E-05 & 0.33327 & 0.750 & 0.250 & 0.961 & 0.719 \\
\hline 0.8 & 272.39 & 0.97161 & $1.14 \mathrm{E}-05$ & 0.02837 & 0.75001 & $2.16 \mathrm{E}-05$ & 0.24997 & 0.800 & 0.200 & 0.972 & 0.777 \\
\hline 0.85 & 270.46 & 0.98103 & $6.16 \mathrm{E}-06$ & 0.01895 & 0.82353 & $1.03 \mathrm{E}-05$ & 0.17645 & 0.850 & 0.150 & 0.981 & 0.834 \\
\hline 0.9 & 268.86 & 0.98846 & $3.13 \mathrm{E}-06$ & 0.01152 & 0.88888 & $4.52 \mathrm{E}-06$ & 0.1111 & 0.900 & 0.100 & 0.989 & 0.890 \\
\hline 0.95 & 267.49 & 0.99464 & $1.20 \mathrm{E}-06$ & 0.00532 & 0.94736 & $1.52 \mathrm{E}-06$ & 0.05262 & 0.950 & 0.050 & 0.995 & 0.945 \\
\hline 0.99 & 266.31 & 0.99989 & $2.04 \mathrm{E}-08$ & 0.0001 & 0.99899 & $2.08 \mathrm{E}-08$ & 0.001 & 0.999 & 0.001 & 1.000 & 0.999 \\
\hline
\end{tabular}

*(1), (2) and (3) denote to isobutene, methanol and MTBE, respectively.

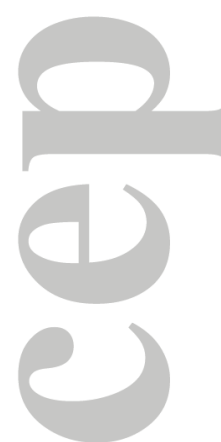

AlChE Journal

This article is protected by copyright. All rights reserved. 
Table 5. Nominal Operating Point of the Optimal Design-control Solution

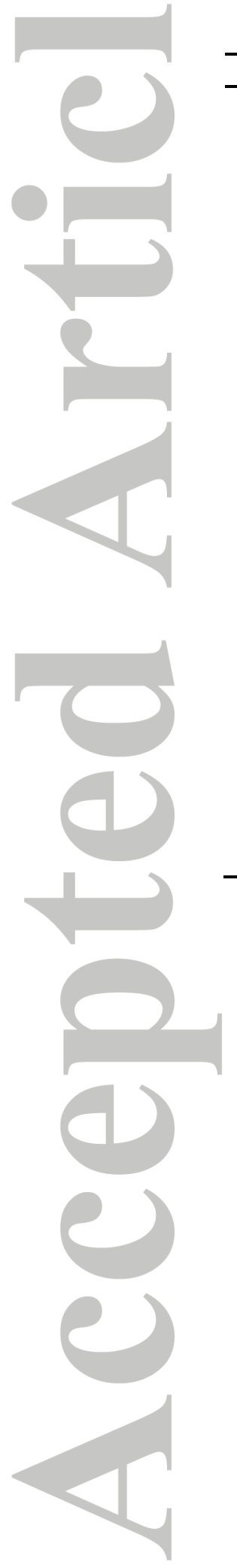

\begin{tabular}{ll}
\hline Variable & Optimal design-control solution \\
\hline Feed Temperature $(\mathrm{K})$ & 300 \\
Distillate Temperature $(\mathrm{K})$ & 265.62 \\
Bottom Temperature $(\mathrm{K})$ & 319.85 \\
Feed flowrate $(\mathrm{kmol} / \mathrm{h})$ & 100 \\
Distillate flowrate $(\mathrm{kmol} / \mathrm{h})$ & 45.543 \\
Bottom flowrate & 29.473 \\
\cline { 2 - 2 } & $z_{\text {isobutene }}^{F}=0.7$ \\
Feed composition $(\mathrm{kmol} / \mathrm{kmol})$ & $z_{\text {methanol }}^{F}=0.3$ \\
& $z_{M T B E}^{F}=0.0$ \\
\cline { 2 - 2 } & $x_{\text {isobutene }}^{D}=0.9795$ \\
Distillate composition $(\mathrm{kmol} / \mathrm{kmol})$ & $x_{\text {methanol }}^{D}=0.0201$ \\
& $x_{M T B E}^{D}=0.314 E-03$ \\
\cline { 2 - 2 } & $x_{\text {isobutene }}^{B}=0.0143$ \\
Bottom composition $(\mathrm{kmol} / \mathrm{kmol})$ & $x_{\text {methanol }}^{B}=0.1405$ \\
& $x_{M T B E}^{B}=0.8451$ \\
\cline { 2 - 2 } Overall methanol conversion & $83.15 \%$ \\
\cline { 2 - 2 } Reboiler duty $(\mathrm{MJ} / \mathrm{h})$ & 294.935 \\
Condenser duty $(\mathrm{MJ} / \mathrm{h})$ & 46.196 \\
Reflux ratio & 2 \\
Heat addition to Reboiler $(\mathrm{kJ} / \mathrm{h})$ & 0 \\
Number of stages & 7 \\
Feed location & Stage 2 \\
\hline
\end{tabular}




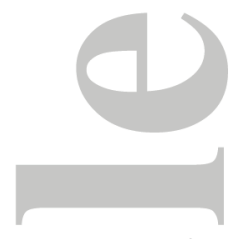

Table 6. Transfer Function Parameters for Design-control Alternatives

\begin{tabular}{ccccc}
\hline $\begin{array}{c}\text { Manipulated variable/ } \\
\text { Controlled variable }\end{array}$ & $\boldsymbol{K}$ & $\tau_{p_{1}}$ & $\tau_{p_{2}}$ & $\tau_{z}$ \\
\hline$R R(s) / x_{M T B E}^{B}(s)$ & $0.32211[-]$ & 6.2527 & 2.324 & -1.8092 \\
$R R(s) / x_{M T B E}^{D}(s)$ & $-4.96 \mathrm{E}-05[-]$ & 2.0042 & 2.004 & 5.3828 \\
$Q_{R}(s) / x_{M T B E}^{B}(s)$ & $-1.23 \mathrm{E}-06[\mathrm{~kJ} / \mathrm{h}]$ & 3.6963 & 3.6821 & -0.64004 \\
$Q_{R}(s) / x_{M T B E}^{D}(s)$ & $-1.47 \mathrm{E}-11[\mathrm{~kJ} / \mathrm{h}]$ & 0.017038 & 0.017038 & -601749 \\
\hline
\end{tabular}




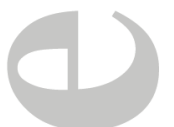

Table 7. The Value of Controller Performance Metrics

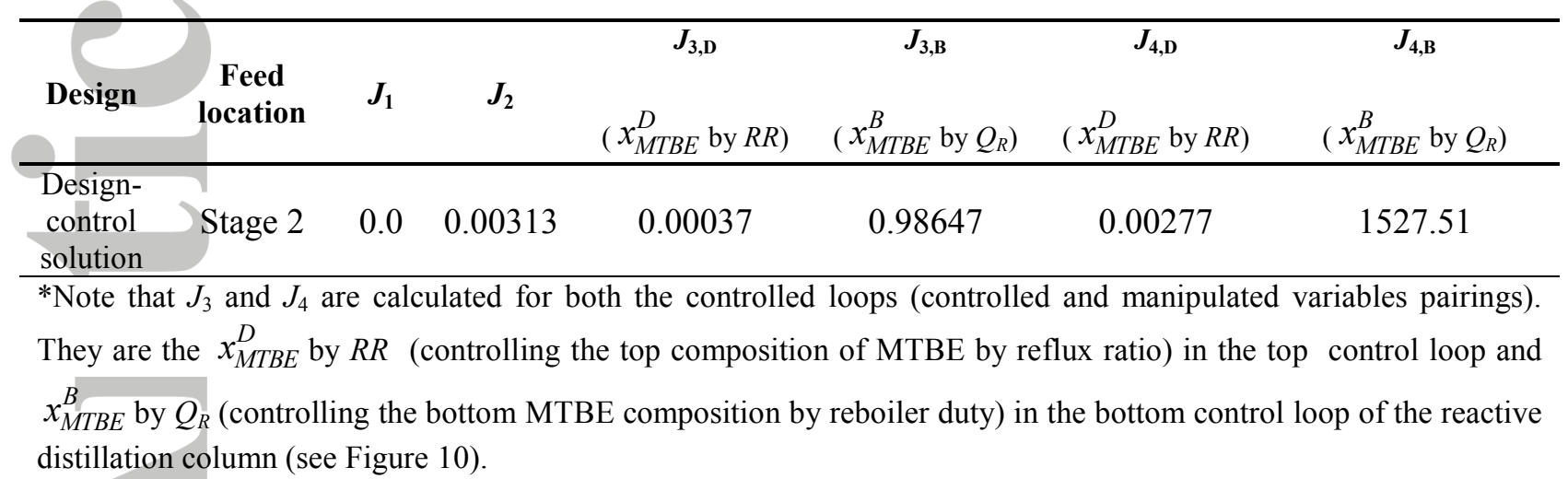
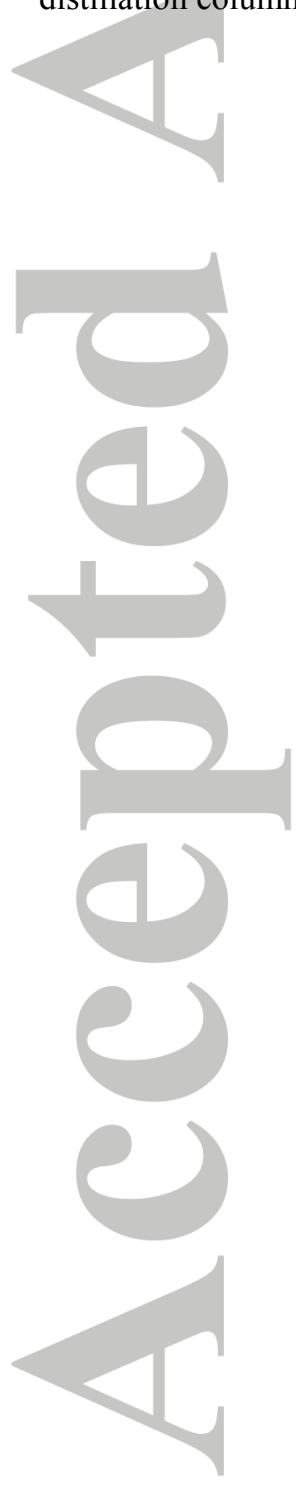


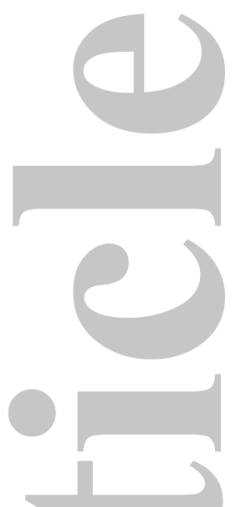

Table 8. Design Alternatives (Not at Maximum Driving Force) for Verification

\begin{tabular}{cccc}
\hline Design alternative & Feed location & Number of stages & Reflux ratio \\
\hline $\mathbf{1}$ & Stage 3 & 7 & 2 \\
$\mathbf{2}$ & Stage 4 & 7 & 2 \\
\hline
\end{tabular}

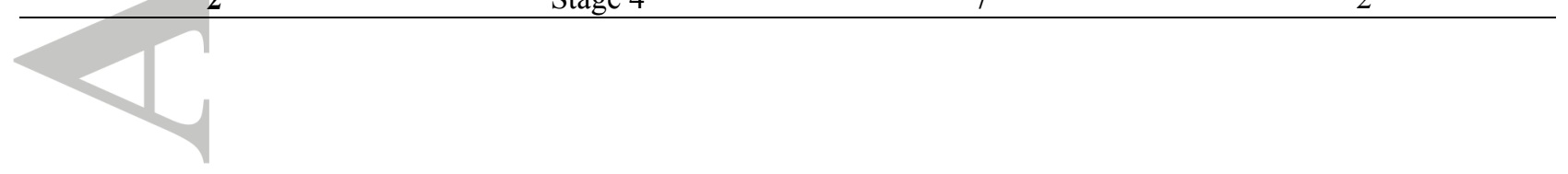

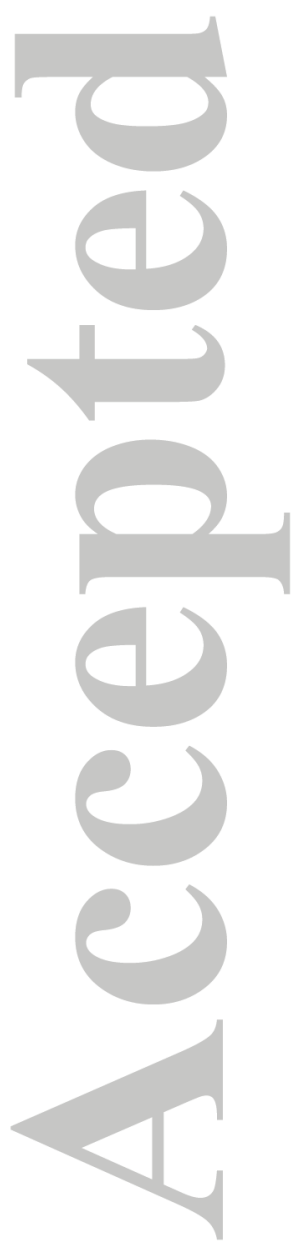




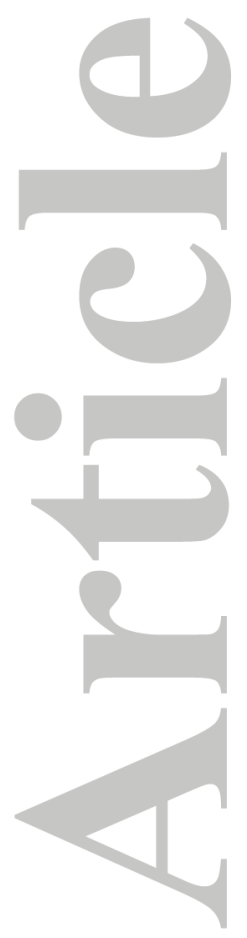

Table 9. The Values of the Controller Performance Metrics for the Design-control Solution and Alternatives (1) and (2)

\begin{tabular}{ccccccc}
\hline & & & $\boldsymbol{J}_{\mathbf{3}, \mathbf{D}}$ & $\boldsymbol{J}_{\mathbf{3}, \mathbf{B}}$ & $\boldsymbol{J}_{\mathbf{4}, \mathbf{D}}$ & $\boldsymbol{J}_{\mathbf{4}, \mathbf{B}}$ \\
\hline Design & $\boldsymbol{J}_{\mathbf{1}}$ & $\boldsymbol{J}_{\mathbf{2}}$ & $\left(x_{M T B E}^{D}\right.$ by $\left.R R\right)$ & $\left(x_{M T B E}^{B}\right.$ by $\left.Q_{R}\right)$ & $\left(x_{M T B E}^{D}\right.$ by $\left.R R\right)$ & $\left(x_{M T B E}^{B}\right.$ by $\left.Q_{R}\right)$ \\
\hline $\begin{array}{c}\text { Design-control } \\
\text { solution }\end{array}$ & 0.0 & 0.00313 & 0.00037 & 0.98647 & 0.00277 & 1527.51 \\
$\begin{array}{c}\text { Design } \\
\text { alternative (1) } \\
\begin{array}{c}\text { Design } \\
\text { alternative (2) }\end{array}\end{array}$ & 0.03 & 0.04375 & 0.02411 & 3.79181 & 0.00025 & 6562.67 \\
\hline
\end{tabular}

**Note that $J_{3}$ and $J_{4}$ are calculated for both the controlled loops (controlled and manipulated variables pairings). They are the $x_{M T B E}^{D}$ by $R R$ (controlling the top composition of MTBE by reflux ratio) in the top control loop and $x_{M T B E}^{B}$ by $Q_{R}$ (controlling the bottom MTBE composition by reboiler duty) in the bottom control loop of the reactive distillation column (see Figure 10).

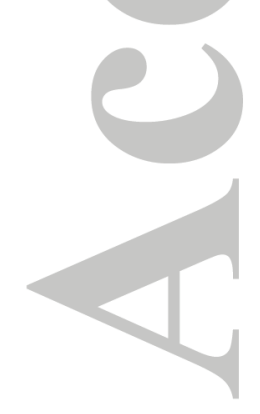




\section{0

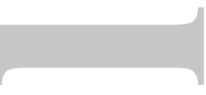

\section{List of Figures}

Figure 1. Driving force based design of distillation columns - on the left is the driving force diagram and on the right is the corresponding design of the reactive distillation column (adapted from Babi and Gani ${ }^{49}$ ).

Figure 2. Dynamic process system representation

Figure 3. Framework of the integrated process design and control of binary element reactive distillation processes.

Figure 4. Schematic drawing of the communication network in a control system.

Figure 5. $T-W_{A}^{v}-W_{A}^{l}$ phase diagram for $\mathrm{MTBE}$ reactive system $(P=101.3 \mathrm{kPa})$.

Figure 6. Reactive distillation column design configuration for design-control solution

Figure 7. Driving force diagram for $W_{A}-W_{B}$ separation (reactive zone only - top figure) and its corresponding derivative of $D F$ with respect to $W_{A}^{l}$ (bottom figure).

Figure 8. Transfer function prediction of $R R / x_{M T B E}^{B}$ pair for the optimal design-control solution (each time sample is $5 \mathrm{~s}$ ).

Figure 9. Open-loop response of optimal design-control solution to a disturbance in the feed (each time sample is $5 \mathrm{~s}$ ).

Figure 10. Simple schematic of control structure implementation. 
Figure 11. Closed-loop performance of optimal design-control solution, operating at the maximum driving to a disturbance in the feed (each time sample is $5 \mathrm{~s}$ ).

Figure 12. Closed-loop performance of Design alternative (1) (each time sample is 5s).

Figure 13. Closed-loop performance of Design alternative (2) (each time sample is 5s).

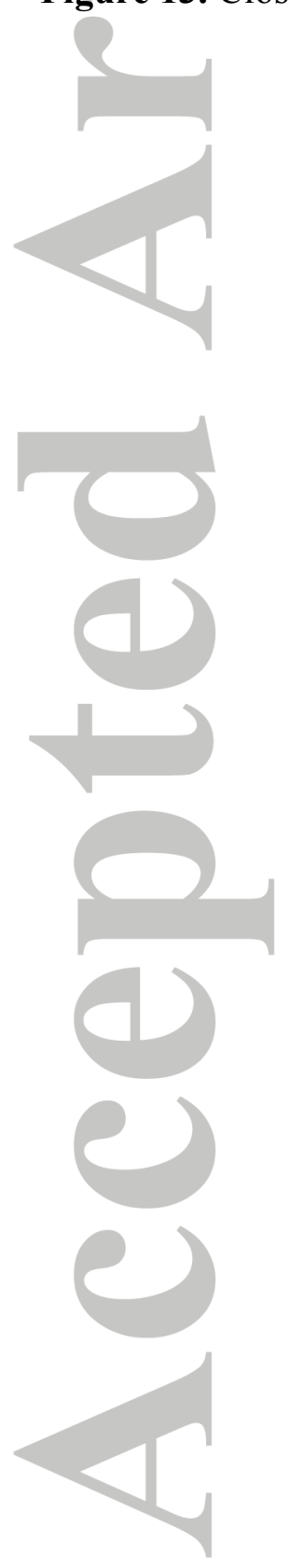




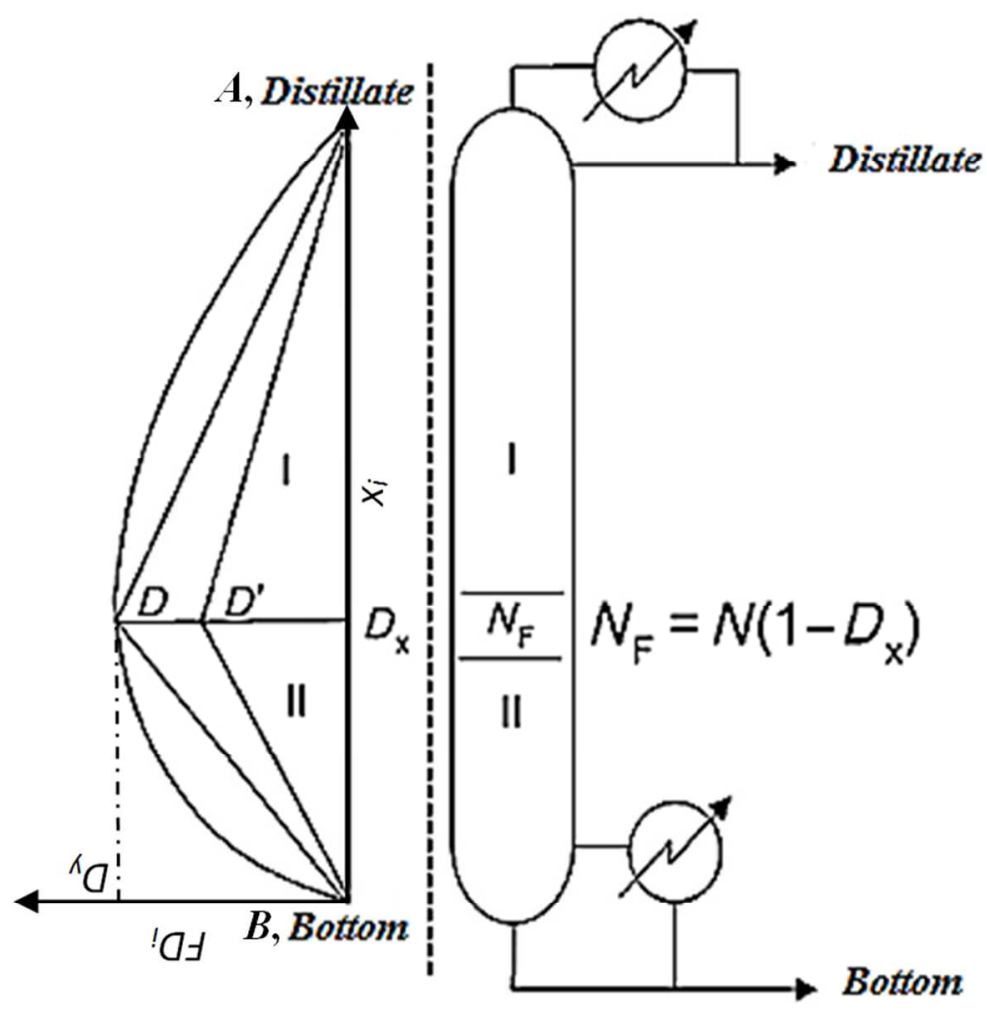

AIChE Journal

This article is protected by copyright. All rights reserved. 
Figure 1: Driving force based design of distillation columns - on the left is the driving force diagram and on the right is the corresponding design of the reactive distillation column (adapted

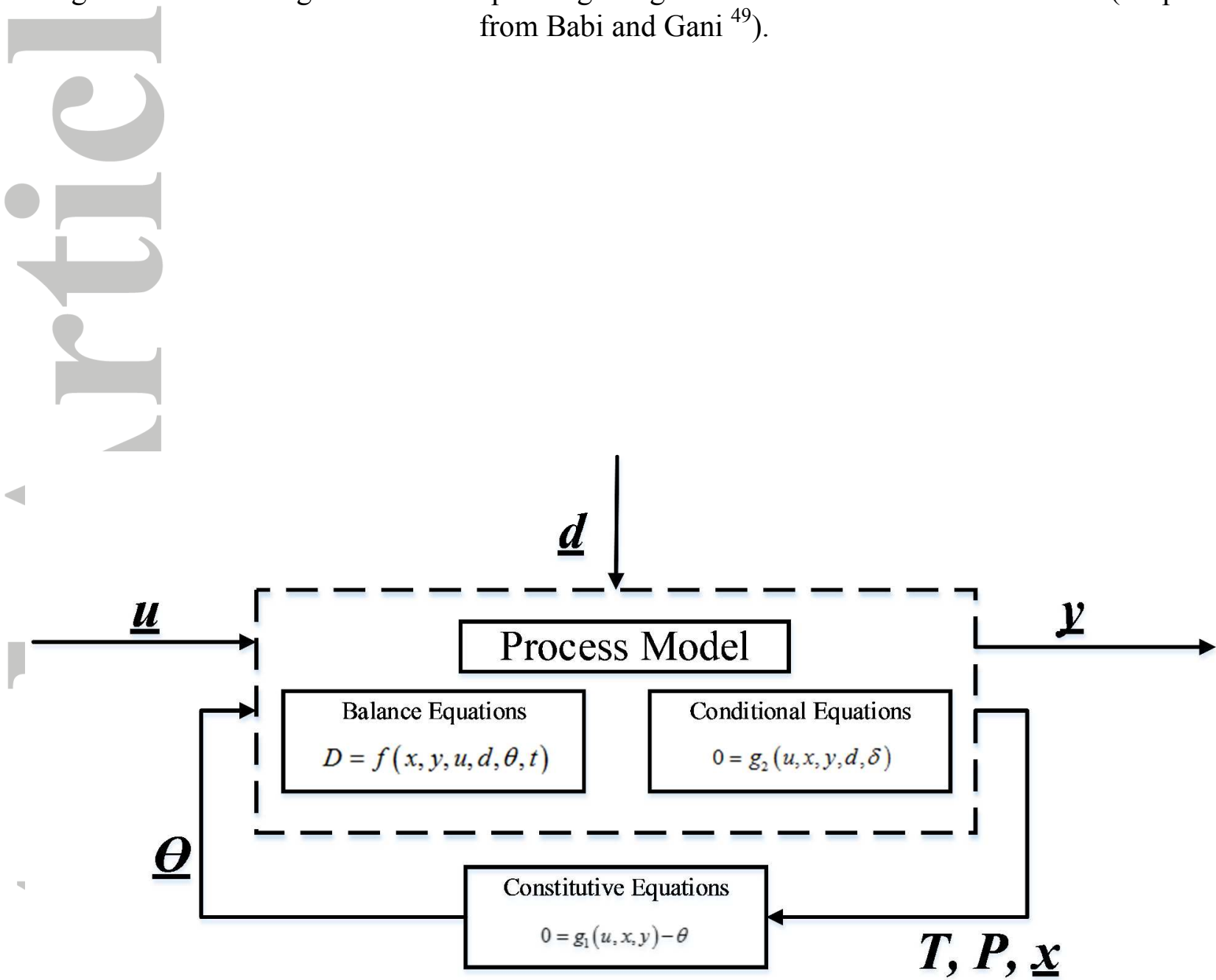

Figure 2: Dynamic process system representation 


\section{Input Information}

- Reactions present in the system and their extent

- Compounds present in the reacting system including

any inert compounds

- Feed specifications (flowrate, temperature, pressure and composition)

- Product specifications (design targets)

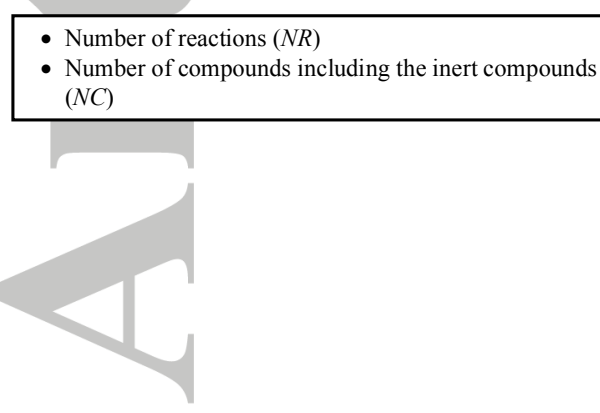

- Formula matirx

- Thermodynamic model and pure component properties - Operating pressure and feed and product specifications based on elements
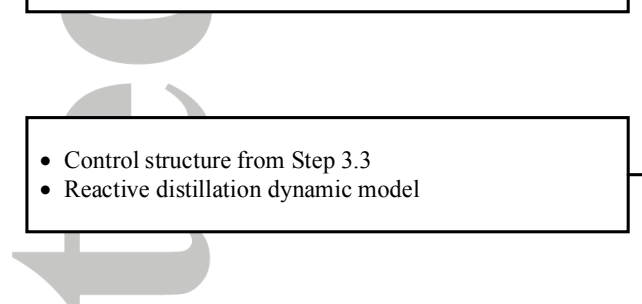
Step 4: Dyanmic analysis and verification
1: Control structure verification (Algorithm 4.1)

4.2: Dynamic evaluation of control structure (Algorithm 4.2) 4.3: Final design selection

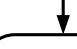

\section{End}

Step 3: Reactive distillation design
3.1: Generate reactive VLE data (Algorithm 3.1)

3.2: Reactive driving force calculations (Algorithm 3.2) 3.3 Optimal design-control alternatives (Algorithm 3.3)
Generated Information

The design targets, feed and product specifications as well as performance objectives are set

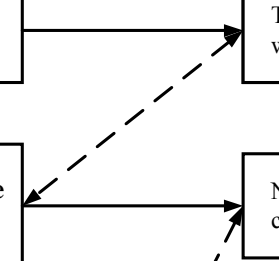

Number of elements is identifed and the formula matrix constructed

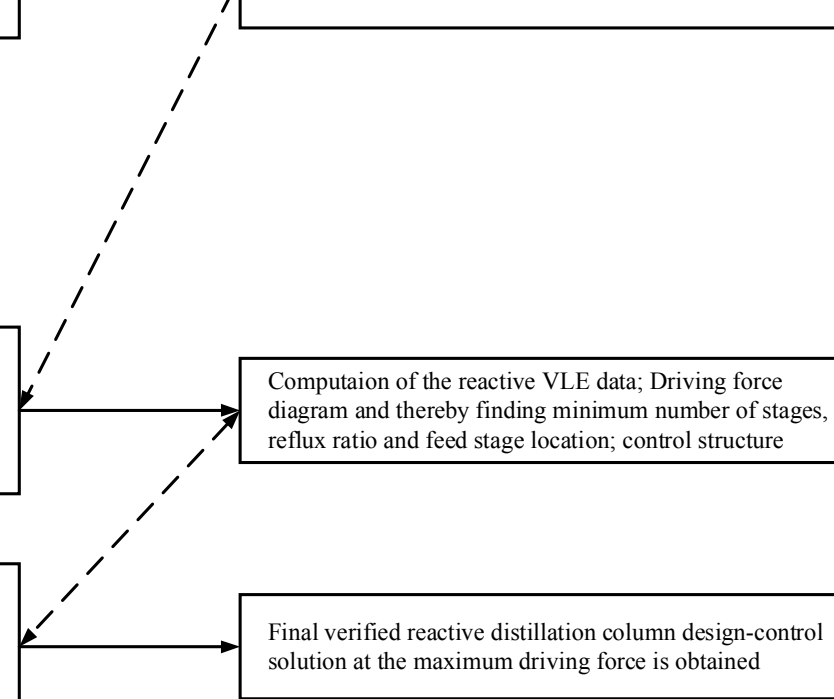

solution at the maximum driving force is obtained

Figure 3: Framework of the integrated process design and control of binary element reactive distillation processes. 


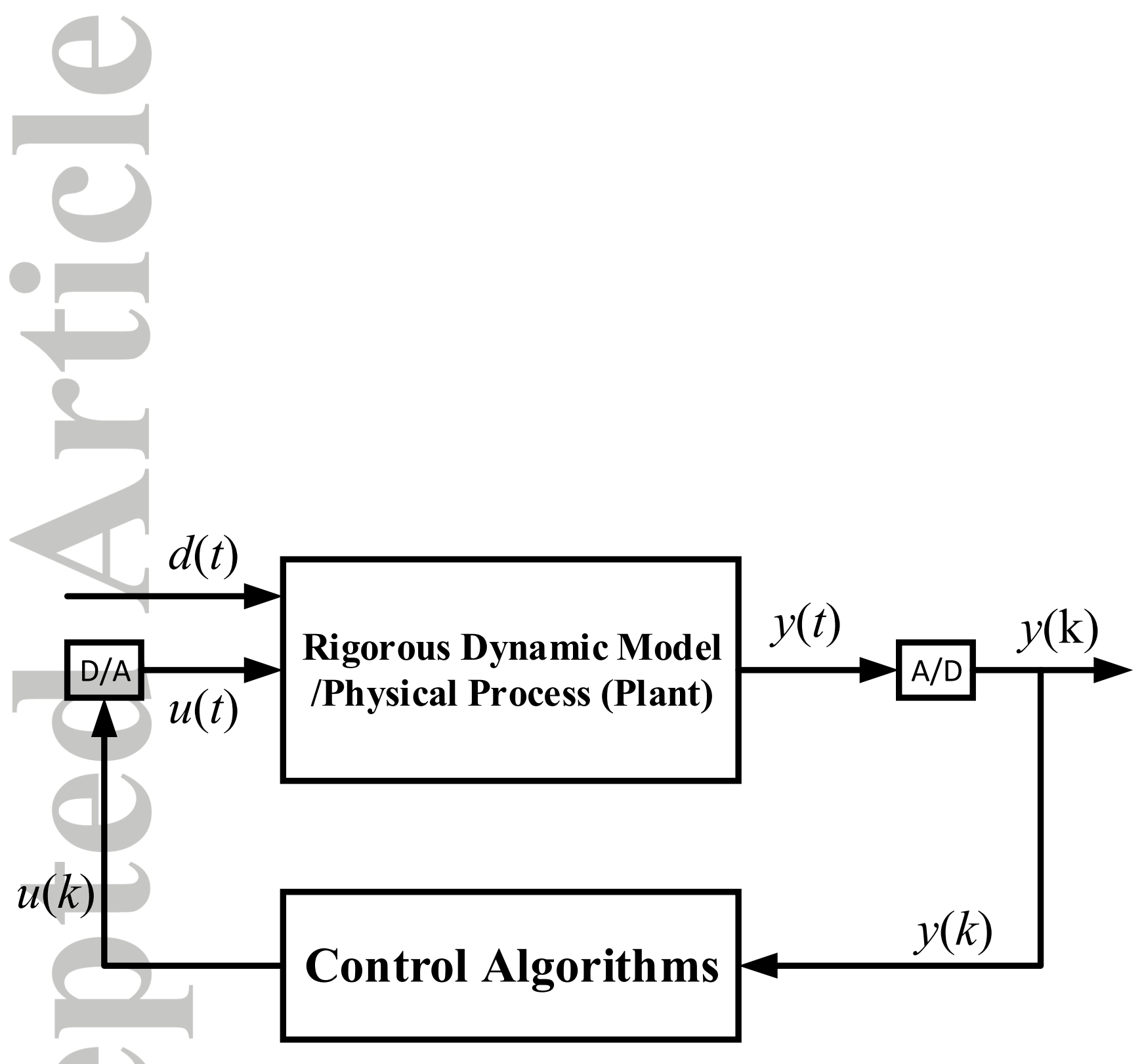

Figure 4: Schematic drawing of the communication network in a control system. 


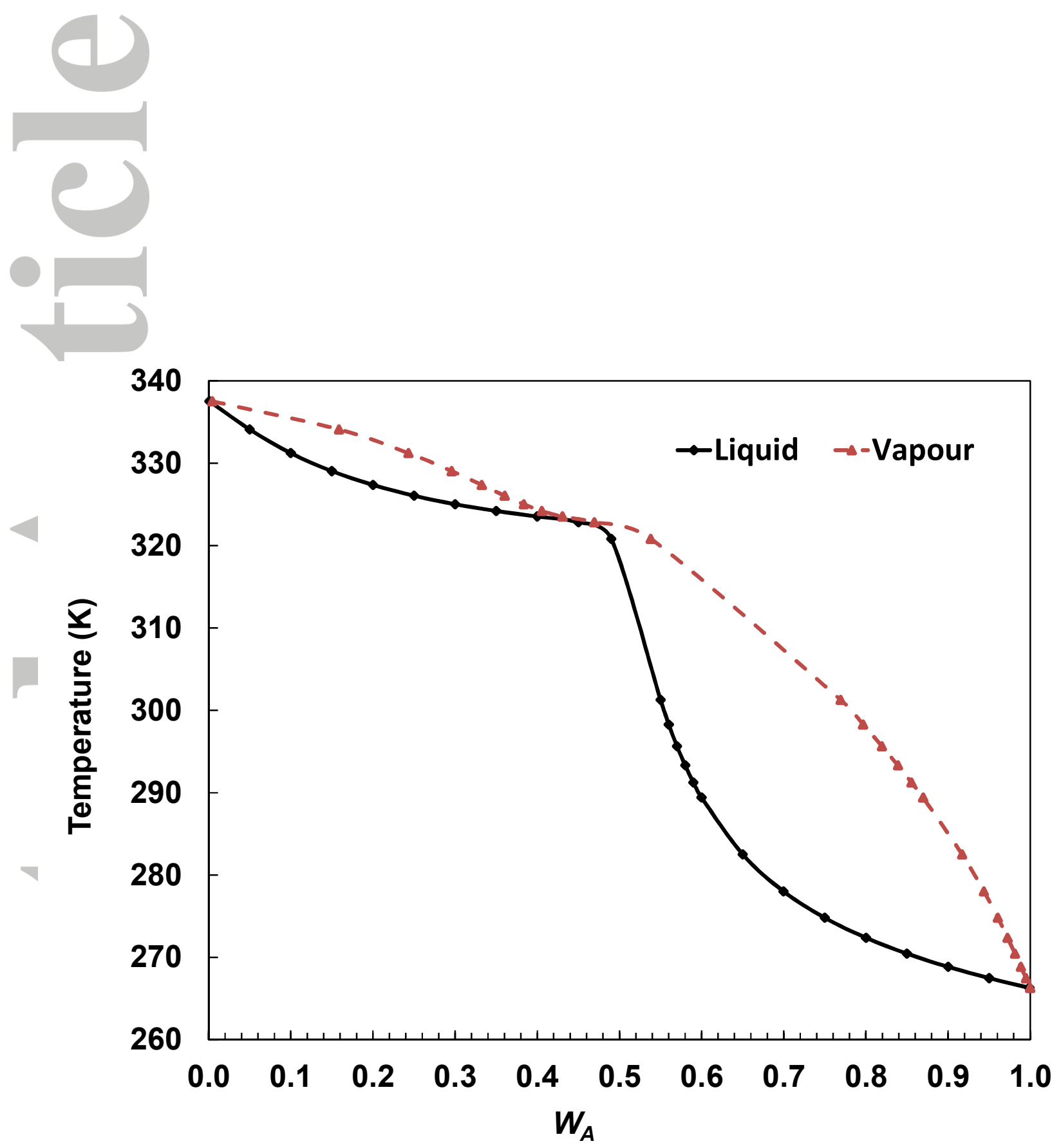

Figure 5: $T-W_{A}^{v}-W_{A}^{l}$ phase diagram for MTBE reactive system $(P=101.3 \mathrm{kPa})$. 


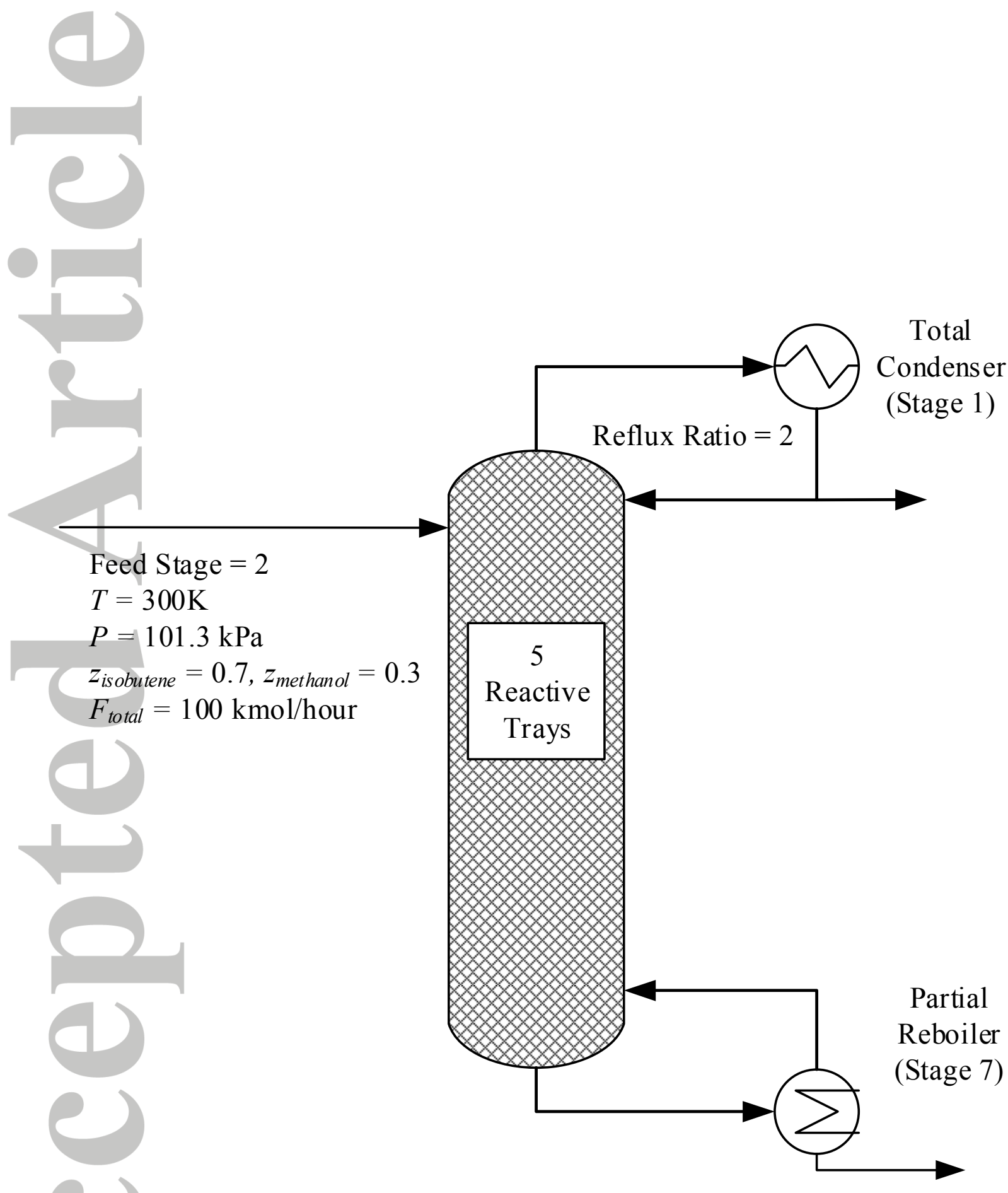

Figure 6: Reactive distillation column design configuration for design-control solution 

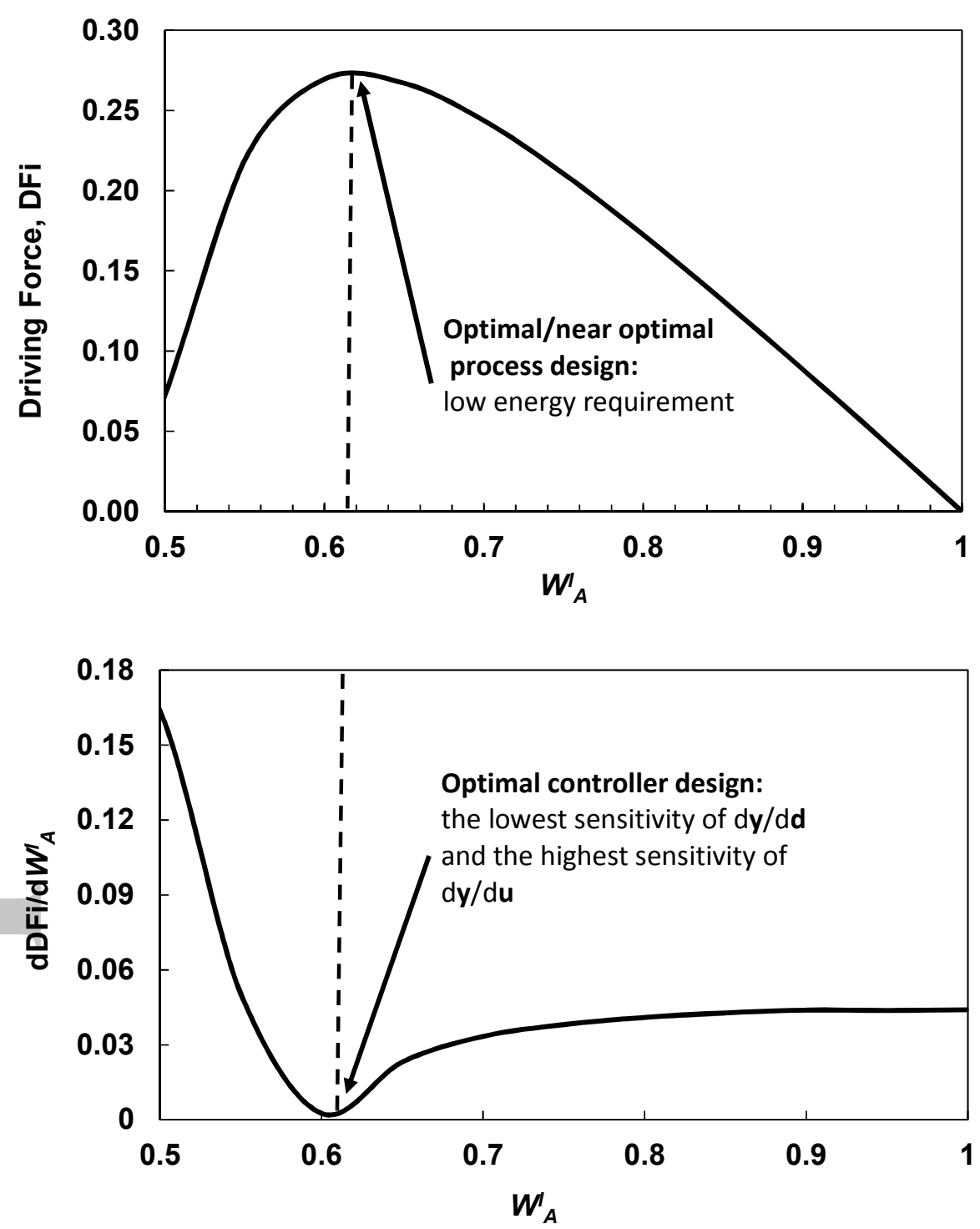

Figure 7: Driving force diagram for $W_{A}-W_{B}$ separation (reactive zone only - top figure) and its corresponding derivative of $D F$ with respect to $W_{A}^{l}$ (bottom figure). 

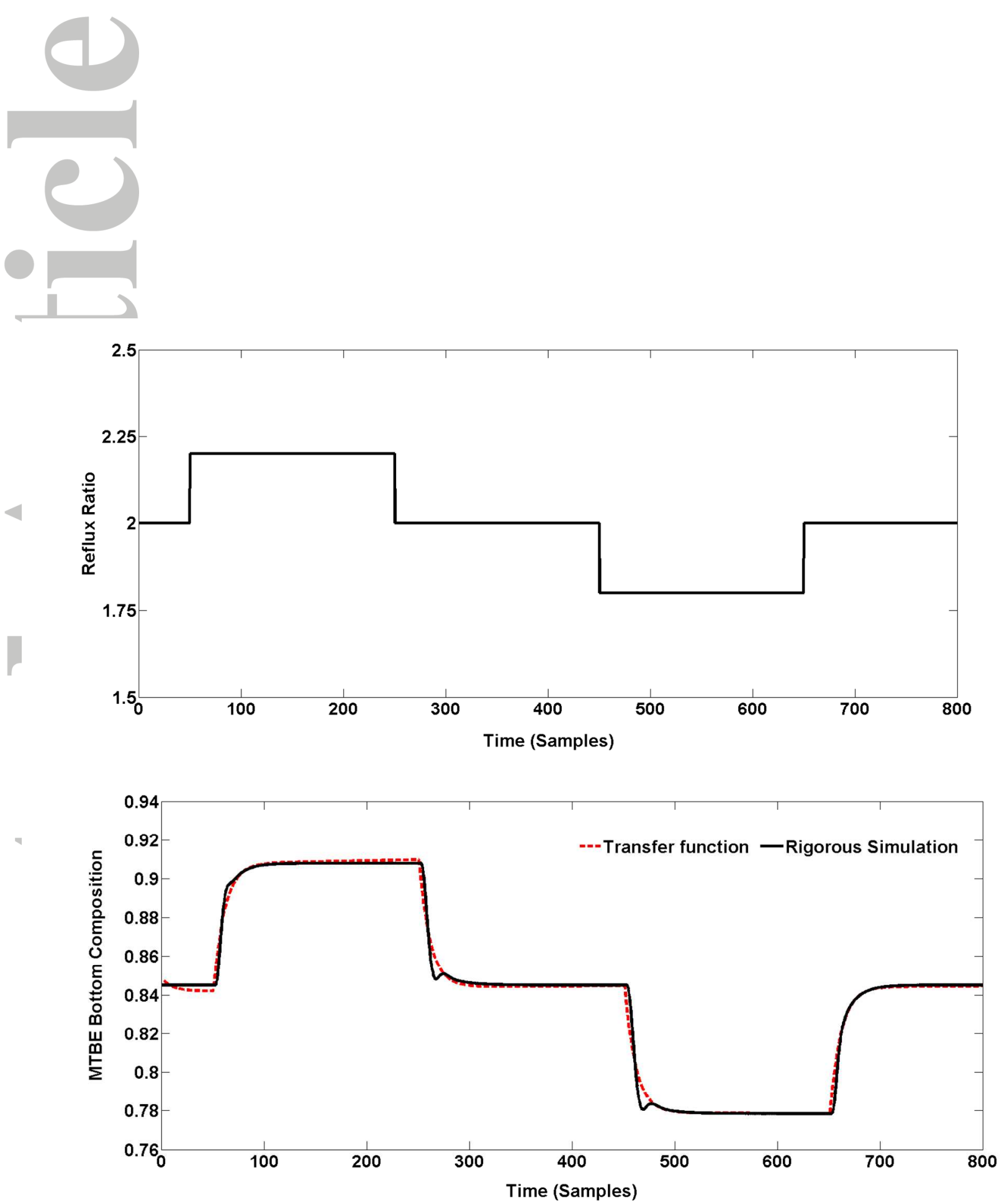

Figure 8: Transfer function prediction of $R R / x_{M T B E}^{B}$ pair for the optimal design-control solution (each time sample is $5 \mathrm{~s}$ )

AlChE Journal

This article is protected by copyright. All rights reserved. 

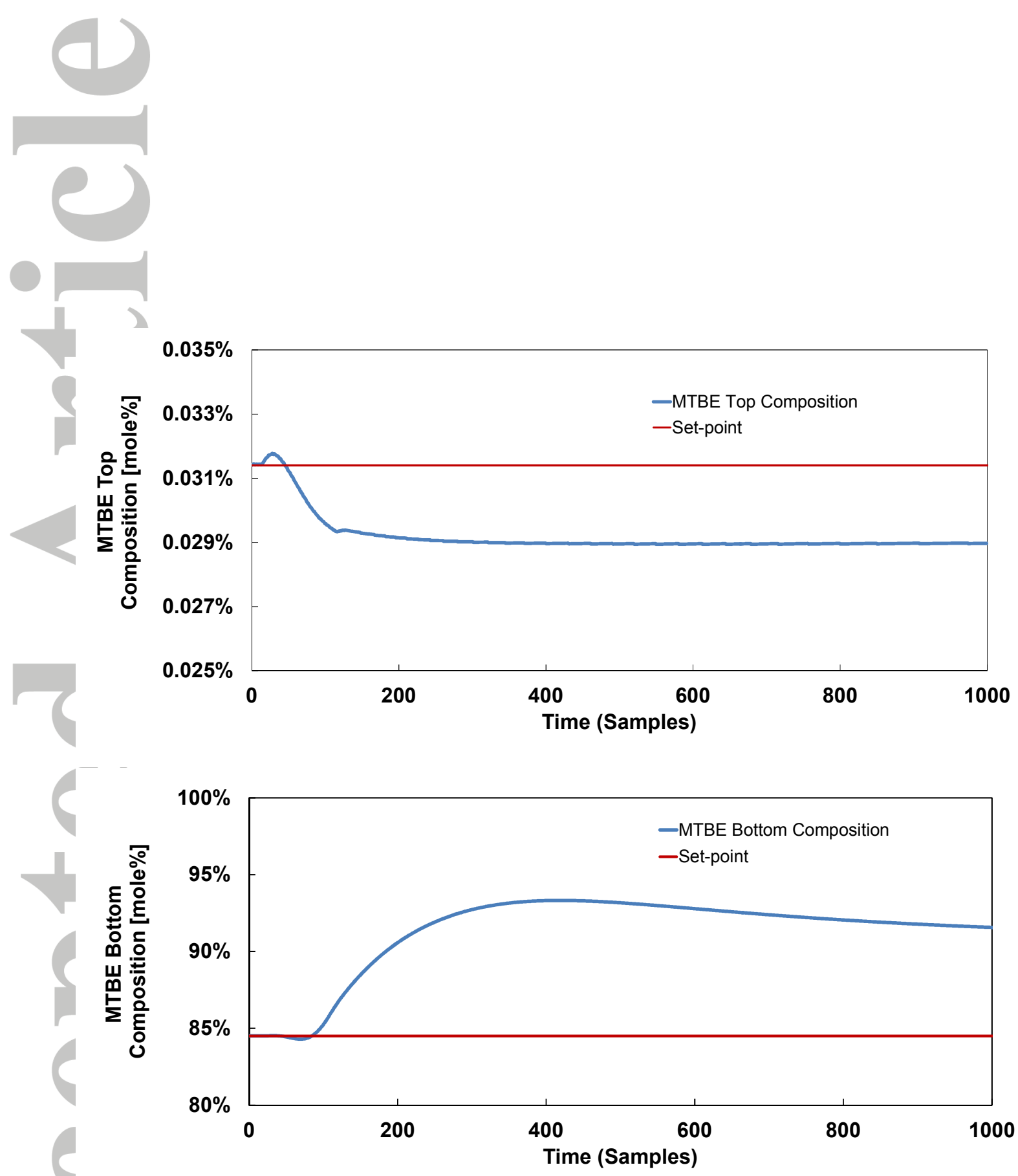

Figure 9: Open-loop response of optimal design-control solution to a disturbance in the feed (each time sample is $5 \mathrm{~s}$ ).

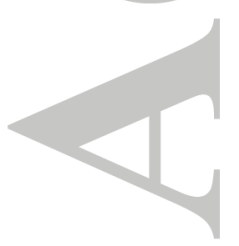




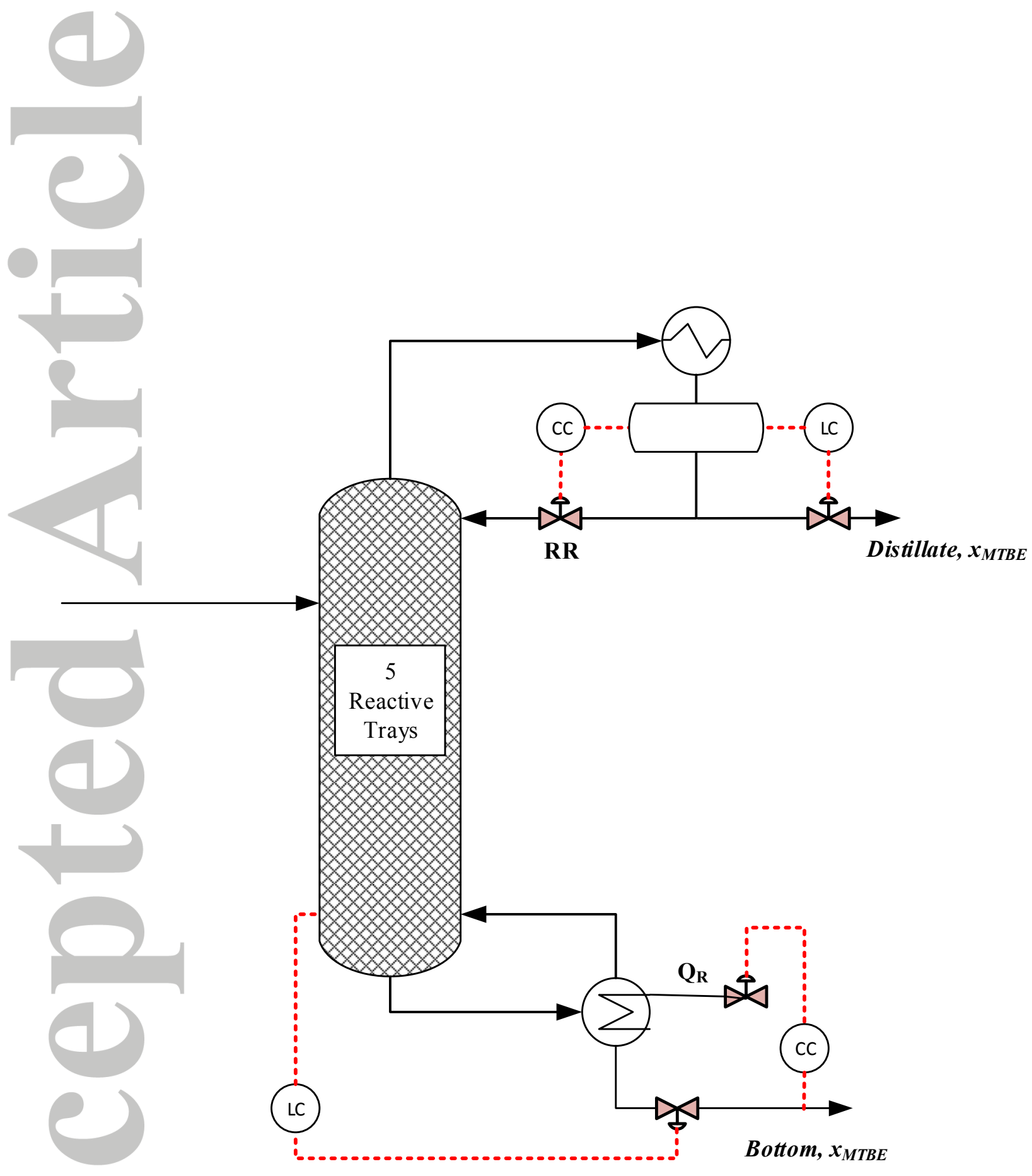

Figure 10: Simple schematic of control structure implementation. 

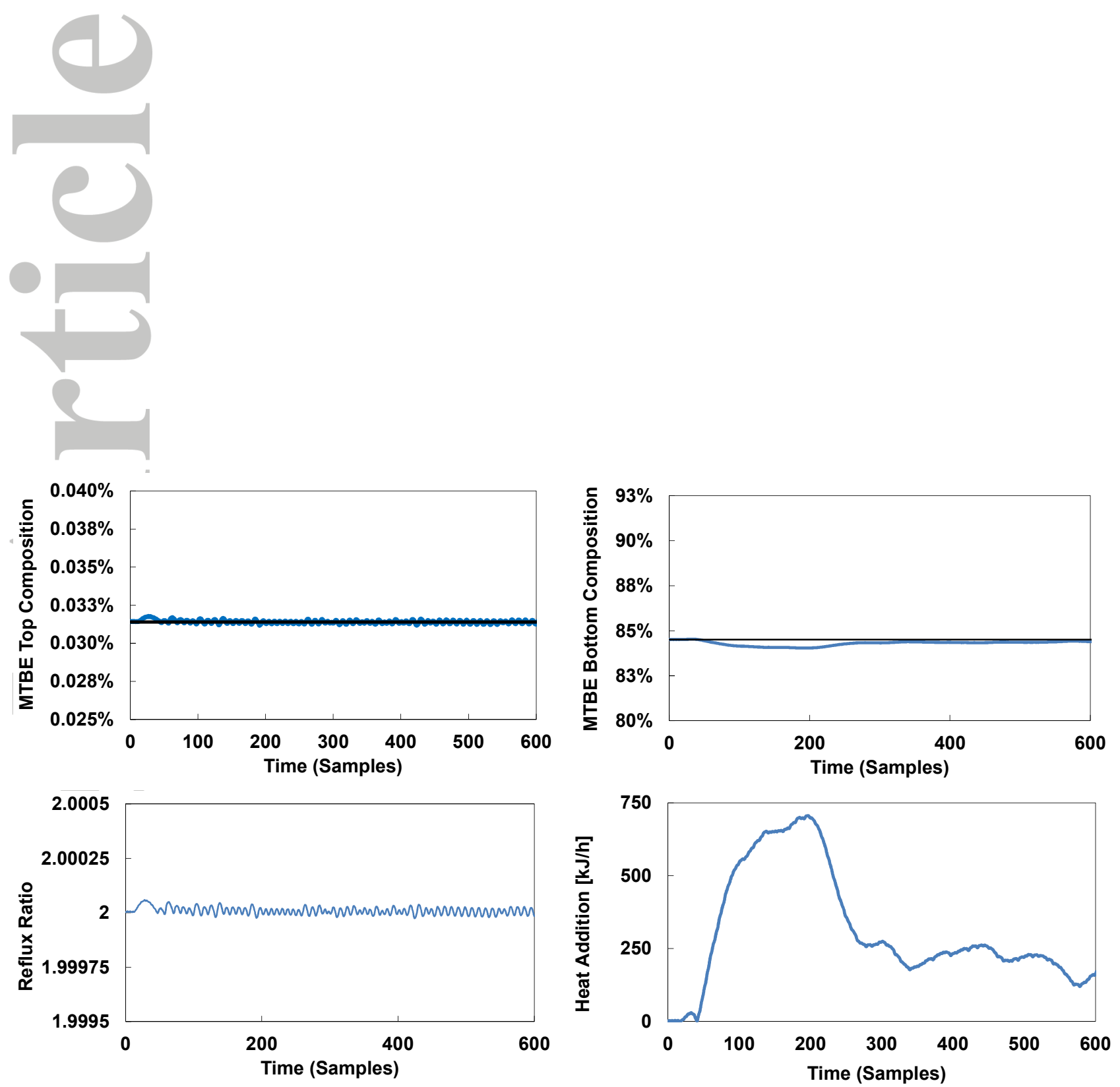

Figure 11: Closed-loop performance of optimal design-control solution, operating at the maximum driving to a disturbance in the feed (each time sample is $5 \mathrm{~s}$ ). 

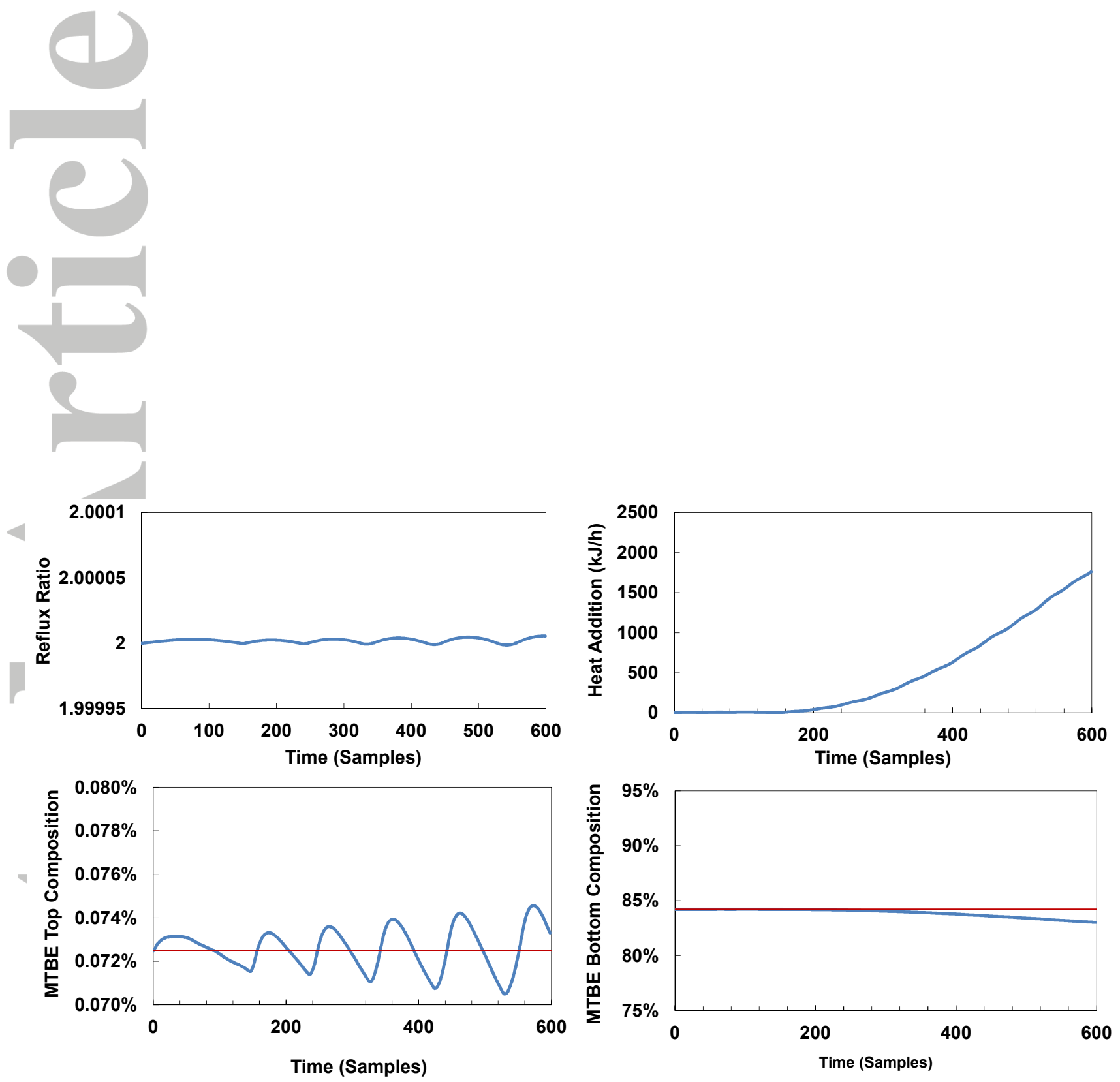

Figure 12: Closed-loop performance of Design alternative (1) (each time sample is 5s).

AlChE Journal

This article is protected by copyright. All rights reserved. 

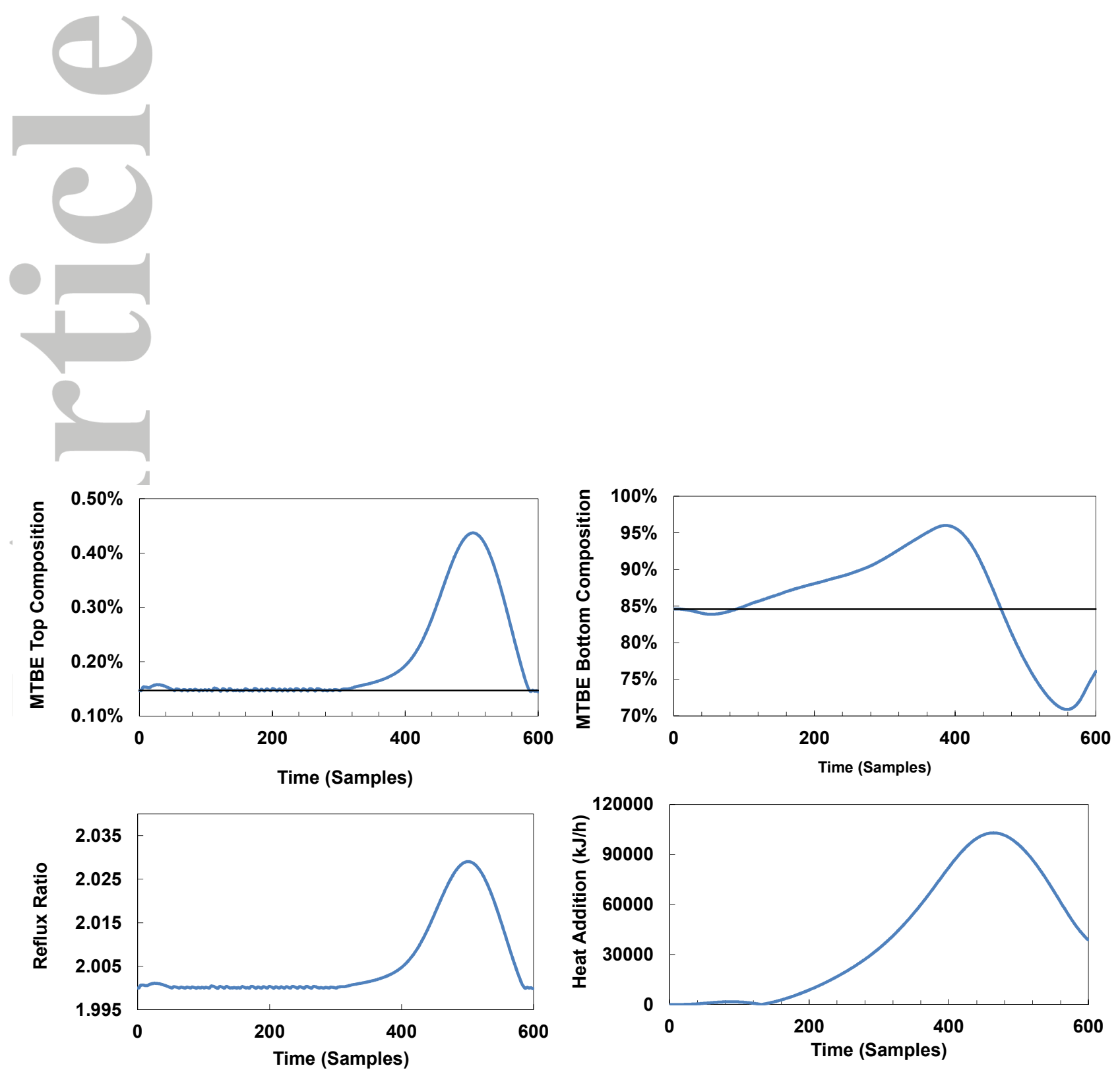

Figure 13: Closed-loop performance of Design alternative (2) (each time sample is 5s).

AlChE Journal

This article is protected by copyright. All rights reserved. 